\title{
Eğimli kritik altı açık kanal akımının sayısal modellemesi
}

\author{
Numerical modelling of sloped sub-critical open channel flow
}

\author{
Veysel GÜMÜŞ⿻̧,a, Alaattin SEVEN ${ }^{1, b}$, Oğuz ŞİMŞEK*1,c \\ ${ }^{1}$ Harran Üniversitesi, Mühendislik Fakültesi, İnşaat Mühendisliği Bölümü, 63290, Şanlıurfa
}

\begin{abstract}
• Geliş tarihi / Received: 09.05.2020 • Düzeltilerek geliş tarihi / Received in revised form: 11.11.2020 • Kabul tarihi / Accepted: 22.11.2020
\end{abstract}
\begin{abstract}
Öz
Bu çalışmada, kritik altı akım koşullarına sahip eğimli açık kanal akımının farklı şartlarda sayısal modellemesi yapılmıştır. Sayısal modellemelerde akımın hareketini sağlayan temel denklemler, sonlu hacimler yöntemine dayalı çözüm yapan ANSYS Fluent paket programı yardımıyla iki boyutlu çözülmüştür. Su yüzü profilinin belirlenmesinde ise Akışkan Hacimleri Yöntemi kullanılmıştır. Sayısal modellemede, türbülansın çözümünde Re-Normalization Group (RNG), Kayma Gerilmesi Taşınımı (Shear Stress Transport-SST), Reynolds Gerilme Modeli (Reynolds Stress Model-RSM) ve Detached Eddy Simülasyon (DES) modelleri kullanılmıştır. Sayısal modelleme sonuçları üzerinde ağ yapısının etkisinin olup olmadığının belirlenmesi için Ağ Yakınsama İndeksi yöntemi kullanılmıştır. Farklı türbülans kapatma modelleri kullanılarak, farklı akım şartlarında elde edilen sayısal hız profilleri deneysel profillerle karşılaştırılmıştır. Karşılaştırma sonucunda, RNG modeli sadece Durum 5'te, SST modeli Durum 1, Durum 6 ve Durum 7'de, RSM modeli Durum 3'te ve DES modeli ise Durum 2 ve Durum 4'te deneysel verilere en yakın tahminde bulunmuştur. Çalışma sonucunda, hafif eğimli kritik altı açık kanal akımının sayısal çözümünde SST modelinin başarılı bir şekilde kullanılabileceği belirlenmiştir.
\end{abstract}

Anahtar kelimeler: Ağ yakınsama indeksi, Akışkan hacimleri yöntemi, Hesaplama ağı, Kritik altı açık kanal akımı, Sayisal model

\begin{abstract}
In this study, numerical modelling of subcritical open channel flow with different conditions has been done. In numerical models, the governing equations are solved in two dimensions with the ANSYS Fluent software, which is based on the finite volume method. Volumes of Fluid Method is used to determine the free surface profile. RNG, SST, RSM and DES models are used to modelling turbulence. Grid Convergence Index method is used to determine the sensitivity of grid structure on the numerical modelling results. The numerical velocity profiles obtained in different cases with different turbulence closure models are compared with the experimental results. According to comparison velocity profiles, the best turbulence closure models are determined RNG for only Case 5, SST for Case 1, Case 6 and Case 7, RSM for Case 3, and DES for Case 2 and Case 4. As a result of the study, it is determined that the SST model can be used successfully in the numerical solution of subcritical flow in sloping open channel.
\end{abstract}

Keywords: Grid convergence index, Volume of fluid, Calculation grid, Subcritical open channel, Numerical model

\footnotetext{
*c Oğuz ŞIMŞEK; oguzsimsek@harran.edu.tr, Tel: (0414) 31830 00/3786 orcid.org/0000-0001-6324-0229

${ }^{a}$ orcid.org/0000-0003-2321-9526 b orcid.org/0000-0003-3698-9749
} 


\section{Giriş}

Akımın 1slak kesitinin tamamen katı sınır ile çevrelenmediği, serbest yüzeyli ve atmosfer basıncına maruz kalan akımlar, açık kanal akımları olarak adlandırılır. Serbest yüzeye sahip bu akımlar, doğal akarsu ve deniz akımları ile yapay açık kanallar, sulama kanaletleri ve kısmı dolu akan kanalizasyon sistemlerinde bulunur (Kırkgöz, 2018).

Ağırlık ve sürtünme kuvvetleri etkisi altında hareket eden açık kanal akımlarının karakteristiklerinin belirlenmesi için farklı parametreler kullanılmaktadır. Bu parametrelerden en önemli olanlarında biri olan Reynolds sayısı ( $R e=4 \rho V R / \mu ; \rho$ akışkan yoğunluğu, $V$ akışkan hızı, $R$ hidrolik yarıçapı ve $\mu$ ise akışkanın dinamik viskozitesi) akımın türbülanslı, laminer ya da geçiş akımı olup olmadığını belirlemek için kullanılan bir büyüklüktür. Reynolds sayısı, atalet kuvvetlerinin viskozite kuvvetlerine oranı olarak tanımlanır ve boyutsuzdur. Buna göre, viskoz kuvvetlerin atalet kuvvetlerine baskın olması durumunda Reynolds sayısı küçülmekte ve akım türü laminer akım özelliklerini taşımaktadır $(\operatorname{Re}<2000)$. Ancak, akımda atalet kuvvetleri viskoz kuvvetlere kıyasla daha baskın olur ise, bu durumda akım türbülanslı akış özelliği taşımaktadır (Re>4000). Her iki akış türünün özelliklerinin meydana gelmesi durumunda ise akış, geçiş akımı olarak değerlendirilir $(2000<\operatorname{Re}<4000)$. Reynolds sayısının yanı sıra, açık kanal akımlarını sınıflandırmak için kullanılan bir diğer önemli büyüklük ise Froude sayısıdır ( $F r=V / \sqrt{g h} ; \mathrm{V}$ akım ortalama hızı, g yerçekimi ivmesi, h su derinliği). Froude sayısı, atalet kuvvetlerinin ağırlık kuvvetlerine oranı olup, boyutsuz bir büyüklüktür. Froude sayısına göre akım, kritik, sel rejimi ya da nehir rejimi olarak sınıflandırılabilir. Fr sayısının birden küçük olması durumunda akım kritik altı yani nehir rejimi, 1'den büyük olması durumunda ise kritik üstü yani sel rejimi olarak adlandırılır. Fr sayısının bire eşit olmas1 durumunda ise akım, kritik akım olarak ifade edilir. Akımın büyük derinlikli, hızlı ve düşük eğimli olması durumunda sıklıkla karşılaşılan nehir rejiminde ağırlık kuvvetleri atalet kuvvetlerinden üstün olmaktadır. Tam aksi durum olarak yani atalet kuvvetlerinin ağırlık kuvvetlerinden büyük olması durumunda meydana gelen sel rejiminde ise akım hızı yüksek, su derinliği ise düşük olmakta ve genellikle dolusavakların şüt kanallarında ve vahşi derelerde meydana gelmektedir. Kritik akım ise nehir rejiminde sel rejimine ya da sel rejiminden nehir rejimine geçişte meydana gelmekte ve akımın özgül enerjisinin en düşük olduğu kesittir (Kırkgöz, 2018).

Açık kanal akımlarının davranışları ve akım karakteristiklerinin belirlenmesi, su ile etkileşimde olan yapıların analiz ve tasarımında oldukça önemlidir. Bu karakteristiklerin incelenmesi için çoğunlukla diferansiyel ve integral yöntemler, boyut analizleri ve deneysel yaklaşımlar kullanılmaktadır. Ancak, özellikle diferansiyel ve integral yöntemler, Navier-Stokes ve enerji denklemlerinin çözümünü gerektirmekte olup, çözümün yapılabilmesi için bazı kabullerin yapılmasını zorunlu kılmaktadır. Yapılan bu kabullerin, çözümü gerçekleştirmede yetersiz kalması durumunda ise sayısal çözüm için farklı analiz yöntemleri kullanılır. Özellikle türbülansın tanımlanabilmesi için son yıllarda sıklıkla başvurulan yöntemlerden biri Hesaplamalı Akışkan Dinamiği (HAD) yöntemleridir (Gumus vd., 2016; Simsek vd., 2016; Soydan vd., 2017; Akoz vd., 2019; Soydan-Oksal vd., 2020; Ayhan vd., 2020). Bu yöntemlerle ise çözümü oldukça zor ve zahmetli olan temel denklemler, farklı türbülans modelleri kullanılarak çözülebilmektedir.

Bu çalışmada, dikdörtgen kesitli, yumuşak eğimli ve kritik altı açık kanal akımı için Ardıçlığlu (1994) tarafindan Lazer Doppler Anemometresi (LDA) kullanılarak, yedi farklı deney durumu için ölçülen akım alanları deneylerle aynı şartlarda, farklı türbülans kapatma modelleri kullanılarak sonlu hacimler yöntemine dayalı bir HAD yazılımı ile sayısal olarak modellenmiştir. Serbest su yüzünün belirlenebilmesi için Akışkan Hacimleri Yöntemi (Volume of Fluids-VOF), türbülansın tanımlanabilmesi için farklı türbülans kapatma modeli kullanılmıştır. A $\breve{g}$ yapısının sayısal çözümler üzerindeki etkisini incelemek ve yapılan sayısal çözümlerin ağ yapısından bağımsız hale geldiğini belirleyebilmek için ise A $\breve{g}$ Yakınsama İndeksi (Grid Convergence Index-GCI) yöntemi kullanılmıştır. Çalışmada, deneysel sonuçlara göre kritik altı açık kanal akımını sayısal olarak modellemede kullanılan modeller arasından en başarılı olan türbülans modeli belirlenmiştir.

\section{Deneysel çalışma}

Deneyler, Ardıçlıoğlu (1994) tarafindan Çukurova Üniversitesi İnşaat Mühendisliği Hidrolik Laboratuvarında Şekil 1'de görülen açık kanal modeli üzerinde yapılmıştır. Deneylerin yapıldığı kanalın yan duvarları ve tabanı camdan imal edilmiştir. Dikdörtgen kesitli açık kanal modelinin boyutları 30x30x700 cm'dir. Suyun sirkülasyonu santrifüj pompa ile yapılmaktadır. Kanal üzerinde 
iki farklı eğimde ve toplam 12 farklı akım koşulunda, $\mathrm{x}=0.60,1.40,1.90,2.40,2.90,3.40$, $3.90,4.40,4.90$ ve $5.40 \mathrm{~m}$ kesitlerinde Lazer
Doppler Anemometresi (LDA) ile hız ölçümleri yapılmıştır. Akım derinliği boyunca yatay hız bileşeninin değişimi elde edilmiştir.

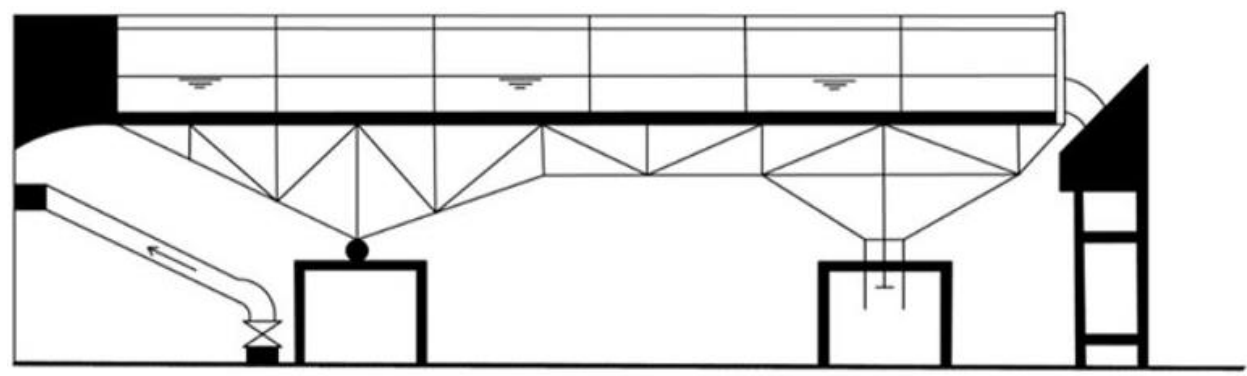

Kanal modeli

$0.75 \mathrm{~m}$

$7 \mathrm{~m}$

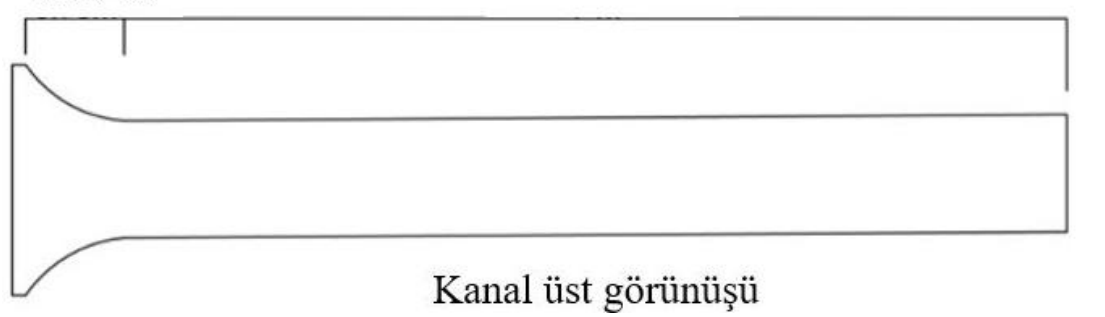

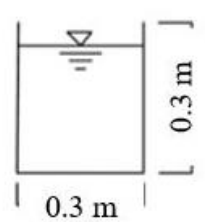

Kanal kesiti

Şekil 1. Deney düzeneğinin şematik görünümü

Deneysel olarak ölçülmüş akım değerleri Tablo 1 'de verilmiştir. Tablodaki eğim değeri kanalın memba yüzünün eğim yüzdesini, $\mathrm{h}_{1}$ su derinliğini, $\mathrm{h}_{1} / \mathrm{b}$ kesit oranını (b, kanal genişliği), Fr sayısı ise kanal girişinde hesaplanan Froude sayısını temsil etmektedir. Farklı akım özelliklerinin temsil edilmesi ve hesaplama zorluklarından dolayı sayısal modellemede tüm deneysel durumların analizleri yapılmamıştır. Sayısal modellemesi yapılan akım değerleri Tablo 1'de italik ve * işareti ile gösterilmektedir.

Tablo 1. Deneylerin akım özellikleri

\begin{tabular}{|c|c|c|c|c|c|}
\hline Deney & Ĕgim & Debi $(\mathbf{l} / \mathbf{s})$ & $\mathbf{h}_{\mathbf{1}}(\mathbf{m m})$ & $\mathbf{h}_{\mathbf{1}} / \mathbf{b}$ & $\mathbf{F r}$ \\
\hline $\mathbf{I}^{*}$ & 0.0005 & 19.5 & 200 & 1.50 & 0.232 \\
\hline $\mathbf{2}^{*}$ & 0.0020 & 19.5 & 100 & 3.00 & 0.656 \\
\hline $\mathbf{3}^{*}$ & 0.0005 & 14.5 & 150 & 2.00 & 0.266 \\
\hline $\mathbf{5}^{*}$ & 0.0005 & 10.0 & 120 & 2.50 & 0.256 \\
\hline $\mathbf{7}^{*}$ & 0.0005 & 6.0 & 75 & 4.00 & 0.311 \\
\hline $\mathbf{9}$ & 0.0005 & 3.2 & 50 & 6.00 & 0.300 \\
\hline $\mathbf{1 0}$ & 0.0005 & 3.2 & 40 & 7.50 & 0.419 \\
\hline $\mathbf{1 1}$ & 0.0005 & 3.2 & 30 & 10.00 & 0.645 \\
\hline $\mathbf{1 2}$ & 0.0020 & 3.2 & 25 & 12.00 & 0.848 \\
\hline
\end{tabular}

\section{Sayisal modelleme}

\subsection{Temel denklemler ve türbülans modelleri}

Kritik altı açık kanal akımı türbülanslı bir akım olup, akımın çözülebilmesi amacıyla kullanılacak temel denklemler süreklilik ve Reynolds Ortalamal1 Navier-Stokes (RANS) denklemleridir. $\mathrm{Bu}$ denklemler, Denklem 1 ve 2'de sirasiyla verilmiştir: $\frac{\partial u_{i}}{\partial x_{i}}=0$

$\rho\left(\frac{\partial u_{i}}{\partial t}+u_{j} \frac{\partial u_{i}}{\partial x_{j}}\right)=\rho g_{i}-\frac{\partial p}{\partial x_{i}}+\mu \frac{\partial^{2} u_{i}}{\partial x_{j}^{2}}+\frac{\partial}{\partial x_{j}}\left(\tau_{\mathrm{ijj}}\right)$

Süreklilik ve RANS denklemlerinde bulunan $u_{i}$ ortalama hız bileşenlerini, $p$ ortalama basıncı, $\mu$ akışkanın dinamik viskozitesini, $\rho$ akışkanın yoğunluğunu, $\rho g_{i}$ yerçekiminin sebep olduğu kütlesel kuvveti, $t$ zaman1, $\tau_{i j}$ ise türbülans (Reynolds) gerilmelerini ifade etmektedir. 
Türbülans yani Reynolds gerilmeleri Boussinesq yaklaşımına göre Denklem 3'teki gibi ifade edilir:

$$
\tau_{\mathrm{ij}}=-\rho \overline{u_{i}^{\prime} u_{j}^{\prime}}=\mu_{t}\left(\frac{\partial u_{i}}{\partial x_{j}}+\frac{\partial u_{j}}{\partial x_{i}}\right)-\frac{2}{3} \delta_{\mathrm{ij}} \rho k
$$

Burada, $u_{\mathrm{i}}^{\prime}$ ve $\mathrm{u}_{\mathrm{j}}^{\prime}$ türbülans hız sapınçları ve $\mu_{\mathrm{t}}$ türbülans viskozitesi olup $\delta_{\mathrm{ij}}$ Kronecker deltadır ( $\mathrm{i}=\mathrm{j}$ için $\delta_{\mathrm{ij}}=1$ ). Türbülans viskozitesinin sayısal olarak hesaplanabilmesi için literatürde sıklıkla kullanılan RNG (Yakhot ve Orszag, 1986; Yakhot vd., 1992), SST (Menter, 1994), RSM (Launder vd., 1975) ve DES (Soydan-Oksal vd., 2020) türbülans modelleri kullanılmıştır. Bu modeller ile ilgili detaylar Gümüş (2014) ve Bal (2019)'da verilmiştir.

\subsection{Akışkan hacimleri yöntemi (Volume of fluid- VOF)}

VOF yöntemi, birbirine karışmayan iki veya daha fazla akışkan arasındaki ara yüzeyin şeklinin belirlenebilmesi için çözüm ağına uygulanabilir (Hirt ve Nichols, 1981). Bu çalışma kapsamında su-hava ara kesitinin belirlenebilmesi için kullanılan bu yöntem, hücrelerin boş, kısmen ya da tamamen su ile dolu olduğunu belirlemede kullanılmaktadır. Buna göre, hacimsel doluluk oranını temsil etmesi için bir akışkan hacmi (F) tanımlanır. $\mathrm{F}=1$ için ağ elemanı tam dolu, $\mathrm{F}=0$ için boş (hava ile dolu) ve $0<\mathrm{F}<1$ için ağ elemanı kısmen dolu olmaktadır. VOF yönteminde ara kesitin hesaplanmasında farklı yaklaşımlar bulunmakla beraber, bu çalışmada "GeoReconstruct" yaklaşımı kullanılmıştır. Bu yöntem ile ilgili detaylar Gümüş (2014)'te verilmiştir.

\subsection{A $\breve{g}$ yakınsama indeksi (Grid convergence index-GCI)}

Sayısal ayrıklaşma duyarlılığının belirlenmesi amacıyla kullanılan GCI yöntemi (Roache, 1994), aynı problemin farklı ağ yapısına ait sayısal sonuçlarının karşıllaştırılmasını içermektedir. Böylece, hesaplama ağ bulguların yakınsaması belirlenmekte ve a ğ geometrisine bağlı belirsizliğin tahmini yapılabilmektedir. Bu yöntemin kullanılabilmesi için en az üç farklı yoğunluktaki hesaplama ağı kullanılmaktadır (Roache, 1998).

Buna göre;

$$
\begin{aligned}
& \mathrm{d}_{3}<\mathrm{d}_{2}<\mathrm{d}_{1}, \mathrm{e}_{12}=\mathrm{u}_{1}-\mathrm{u}_{2}, \quad \mathrm{e}_{23}=\mathrm{u}_{2}-\mathrm{u}_{3}, \quad \mathrm{r}_{12}=\frac{\mathrm{d}_{1}}{\mathrm{~d}_{2}}, \quad \mathrm{r}_{23}=\frac{\mathrm{d}_{2}}{\mathrm{~d}_{3}} \\
& \mathrm{p}=\frac{1}{\ln \left(\mathrm{r}_{23}\right)} \ln \left(\frac{\left(\mathrm{r}_{23}^{\mathrm{p}}-1\right) \mathrm{e}_{12}}{\left(\mathrm{r}_{12}^{\mathrm{p}}-1\right) \mathrm{e}_{23}}\right) \\
& \mathrm{E}_{23}=\frac{\mathrm{u}_{3}-\mathrm{u}_{2}}{\mathrm{u}_{3}} \\
& \mathrm{GCI}_{23}^{\text {ince }}=F_{s} \frac{\left|\mathrm{E}_{23}\right|}{\mathrm{r}_{23}^{\mathrm{p}}-1}
\end{aligned}
$$

Burada bulunan $d_{1}, d_{2}$ ve $d_{3}$ sirasiyla A $\breve{g} 1, A \breve{g} 2$ ve A $\breve{g} 3$ 'te bulunan ağ elemanının yüksekliğini ifade etmektedir. $u_{1}, u_{2}$ ve $u_{3}$ sirasiyla A $\breve{g} 1, A \breve{g} 2$ ve A $\breve{g}$ 3 'te belirlenen noktadaki akışkanın hızını ifade etmektedir. $\mathrm{p}$ ifadesi de doğruluk mertebesini, $\mathrm{F}_{\mathrm{s}}$ ise güvenlik faktörünü belirtmektedir. $\mathrm{e}_{12}$ ve $\mathrm{e}_{23} \mathrm{~h}$ hz farklarını, $r_{12}$ ve $r_{23}$ ise ağ elemanının yükseklik oranını ifade etmektedir. Buna göre $r_{23}, r_{12} \geq 1.10$ olmalı ve üç veya daha fazla ağ yapısı için güvenlik faktörü $F_{s}, 1.25$ olarak önerilmektedir (Roache, 1994; Roache, 1998). İşlem sonucunda hesaplanan $\mathrm{GCI}_{23}^{\text {ince }}$ değeri \%2'den daha küçük ise ağa bağlı sayısal hesaplama sonuçlarının kabul edilebilir hata sinırlarında olduğu ve hesaplama hassasiyetinin ağ yoğunluğundan bağımsızlaşttğg 1 sonucuna varılır. Bu yöntemde gerekli olan üç farklı ağ yapısı, ağ sıklığının $\% 25$ ve $\% 50$ arttırılması suretiyle oluşturulmuş ve oluşturulan \%50 sıklaştırılmış ağ, en iyi ağ yani ince ağ olarak adlandırılmıştır (Şekil 2). Bu çalışmada iki farklı akım durumu için üç farklı sıklıkta ağ yapısı kullanılmış ve sayısal çözüm bölgesi iki alt bölgeye ayrılmıştır. GCI yöntemi için oluşturulan farklı yoğunluktaki hesaplama ağlarına ait eleman sayılarına ait detaylar Tablo 2'de verilmiştir. 


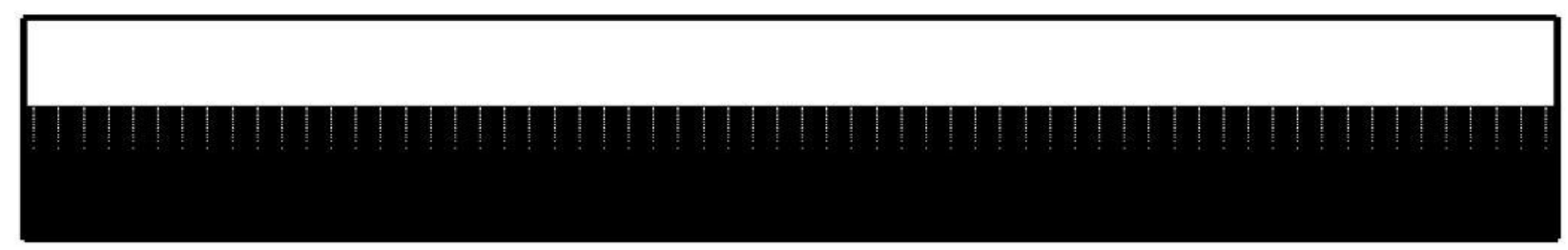

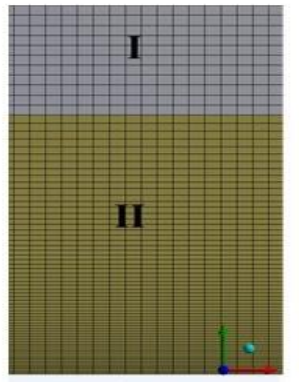

Ăg 1

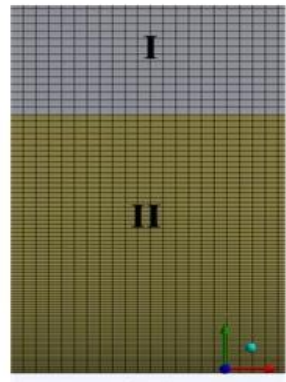

A

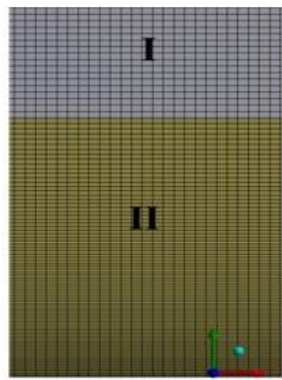

Ă 3

Şekil 2. Hesaplama ağ

Tablo 2. Farklı alt bölgelerde bulunan ağ elemanı sayıları

\begin{tabular}{|c|c|c|c|c|}
\hline Durum & Alt Bölge & Ăg 1 & $\mathbf{A \breve { g }} 2$ & $\mathbf{A \breve { g } 3}$ \\
\hline \multirow{2}{*}{ I. Durum } & I. Bölge & $13 \times 667$ & $17 \times 833$ & $20 \times 1000$ \\
\hline & II. Bölge & $63 \times 667$ & $17 \times 833$ & $95 \times 1000$ \\
\hline \multirow{2}{*}{ IX. Durum } & I. Bölge & $53 \times 667$ & $65 \times 833$ & $80 \times 1000$ \\
\hline & II. Bölge & $23 \times 667$ & $30 \times 833$ & $35 \times 1000$ \\
\hline
\end{tabular}

En düşük ve en yüksek giriş su yüksekliklerine sahip iki debide farklı kesitlerde, GCI analizleri yapılmıştır. Ağ yakınsama indeksi yöntemi ile Durum 1 için $\mathrm{x}=290$ ve 390 cm'de 10 farklı derinlikte elde edilen sonuçlar sırasıyla Tablo 3 ve 4 'te verilmiştir. Buna göre, ele alınan diğer akım durumlarına göre hız değerleri yüksek olan Durum 1 için $\mathrm{x}=290 \mathrm{~cm}$ 'de elde edilen en küçük ve en büyük $\mathrm{GCI}_{23}^{\text {ince }}$ değerleri sırasıyla \% 0.001 ile \% 0.935 olarak belirlenmiștir. Katı sınıra yakın olan bölgede akım hızlarının viskoz gerilmeler neticesinde hızlı değişimlere uğraması nedeniyle en yüksek $\mathrm{GCI}_{23}^{\text {ince }}$ değerleri katı sınıra yakın olan bölgede elde edilmiştir. Ayrıca, akımın katı sınır etkisinden çıkmaya başladığı noktadan itibaren $\mathrm{GCI}_{23}^{\text {ince }}$ değerleri azalma eğilimine girmiştir. Yine Durum 1 için $x=390 \mathrm{~cm}$ kesitinde, $x=290 \mathrm{~cm}$ 'ye benzer bir şekilde katı sınıra yakın olan bölgede GCI değerleri daha yüksek olarak \% 0.018 değerinde olurken, katı sınırdan uzaklaştıkça büyük bir azalma göstermiştir. Bu nedenle, Durum 1 için elde edilmiş olan GCI değerlerine göre, kullanılan ağ yapısının çözüm üzerine etkisinin olmadığı belirlenmiştir.

Tablo 3. Durum 1 için $x=290$ cm'deki GCI sonuçları

\begin{tabular}{|c|c|c|c|c|c|c|c|c|c|c|}
\hline $\mathbf{n}(\mathbf{m m})$ & $\mathbf{d}_{\mathbf{1}}(\mathbf{m m})$ & $\mathbf{d}_{\mathbf{2}}(\mathbf{m m})$ & $\mathbf{d}_{\mathbf{3}}(\mathbf{m m})$ & $\mathbf{U}_{\mathbf{s} 1}$ & $\mathbf{U}_{\mathbf{s} 2}$ & $\mathbf{U}_{\mathbf{s} 3}$ & $\mathbf{r}_{\mathbf{1}}$ & $\mathbf{r}_{\mathbf{2}}$ & $\mathbf{p}$ & $\mathbf{G C I}$ \\
\hline $\mathbf{1 0}$ & 1.866 & 1.494 & 1.195 & 0.268 & 0.267 & 0.266 & 1.249 & 1.250 & -4.769 & $\mathbf{- 0 . 9 3 5}$ \\
\hline $\mathbf{2 0}$ & 2.511 & 1.965 & 1.612 & 0.301 & 0.301 & 0.300 & 1.278 & 1.219 & -8.334 & $\mathbf{- 0 . 6 9 9}$ \\
\hline $\mathbf{3 0}$ & 2.501 & 2.001 & 1.666 & 0.326 & 0.326 & 0.324 & 1.250 & 1.201 & -22.297 & $\mathbf{- 0 . 5 3 8}$ \\
\hline $\mathbf{4 0}$ & 2.499 & 1.690 & 1.666 & 0.349 & 0.349 & 0.348 & 1.479 & 1.014 & -23.565 & $\mathbf{- 0 . 3 5 3}$ \\
\hline $\mathbf{5 0}$ & 3.033 & 1.666 & 2.499 & 0.365 & 0.366 & 0.365 & 1.821 & 0.667 & -23.565 & $\mathbf{- 0 . 3 5 3}$ \\
\hline $\mathbf{7 0}$ & 3.758 & 2.997 & 2.499 & 0.376 & 0.377 & 0.376 & 1.254 & 1.199 & 1.648 & $\mathbf{0 . 3 1 1}$ \\
\hline $\mathbf{9 0}$ & 4.002 & 2.852 & 2.499 & 0.379 & 0.380 & 0.379 & 1.403 & 1.141 & -1.595 & $\mathbf{- 0 . 5 5 9}$ \\
\hline $\mathbf{1 1 0}$ & 4.000 & 2.861 & 2.499 & 0.379 & 0.382 & 0.382 & 1.398 & 1.145 & 4.855 & $\mathbf{0 . 1 1 0}$ \\
\hline $\mathbf{1 4 0}$ & 3.749 & 3.006 & 2.499 & 0.383 & 0.384 & 0.383 & 1.247 & 1.203 & 3.356 & $\mathbf{0 . 0 9 7}$ \\
\hline $\mathbf{1 8 0}$ & 3.848 & 3.124 & 2.499 & 0.369 & 0.367 & 0.367 & 1.232 & 1.250 & 14.350 & $\mathbf{0 . 0 0 1}$ \\
\hline
\end{tabular}


Tablo 4. Durum 1 için $x=390$ cm'deki GCI sonuçları

\begin{tabular}{|c|c|c|c|c|c|c|c|c|c|c|}
\hline $\mathbf{n}(\mathbf{m m})$ & $\mathbf{d}_{\mathbf{1}}(\mathbf{m m})$ & $\mathbf{d}_{\mathbf{2}}(\mathbf{m m})$ & $\mathbf{d}_{\mathbf{3}}(\mathbf{m m})$ & $\mathbf{U}_{\mathbf{s 1}}$ & $\mathbf{U}_{\mathbf{s 2}}$ & $\mathbf{U}_{\mathbf{s 3}}$ & $\mathbf{r}_{\mathbf{1}}$ & $\mathbf{r}_{\mathbf{2}}$ & $\mathbf{p}$ & $\mathbf{G C I}$ \\
\hline $\mathbf{1 0}$ & 1.879 & 1.491 & 1.200 & 0.265 & 0.264 & 0.263 & 1.260 & 1.243 & -1.843 & $\mathbf{- 0 . 0 1 8}$ \\
\hline $\mathbf{2 0}$ & 2.507 & 1.972 & 1.607 & 0.297 & 0.296 & 0.295 & 1.272 & 1.227 & -1.975 & $\mathbf{- 0 . 0 1 5}$ \\
\hline $\mathbf{3 0}$ & 2.503 & 2.003 & 1.666 & 0.318 & 0.318 & 0.317 & 1.249 & 1.202 & -4.860 & $\mathbf{- 0 . 0 0 8}$ \\
\hline $\mathbf{4 0}$ & 2.498 & 1.666 & 1.665 & 0.337 & 0.337 & 0.336 & 1.499 & 1.001 & -13.331 & $\mathbf{- 0 . 0 0 7}$ \\
\hline $\mathbf{5 0}$ & 3.034 & 3.031 & 2.500 & 0.356 & 0.355 & 0.354 & 1.001 & 1.212 & 18.719 & $\mathbf{0 . 0 0 0}$ \\
\hline $\mathbf{7 0}$ & 3.752 & 2.997 & 2.500 & 0.379 & 0.379 & 0.379 & 1.252 & 1.199 & -1.733 & $\mathbf{- 0 . 0 0 4}$ \\
\hline $\mathbf{9 0}$ & 4.001 & 2.857 & 2.497 & 0.383 & 0.384 & 0.383 & 1.400 & 1.144 & -3.114 & $\mathbf{- 0 . 0 0 3}$ \\
\hline $\mathbf{1 1 0}$ & 4.001 & 2.857 & 2.500 & 0.385 & 0.386 & 0.385 & 1.400 & 1.143 & -2.742 & $\mathbf{- 0 . 0 0 3}$ \\
\hline $\mathbf{1 4 0}$ & 3.748 & 3.003 & 2.497 & 0.387 & 0.387 & 0.387 & 1.248 & 1.203 & 2.437 & $\mathbf{0 . 0 0 1}$ \\
\hline $\mathbf{1 8 0}$ & 3.846 & 3.127 & 2.500 & 0.372 & 0.371 & 0.370 & 1.230 & 1.250 & 0.641 & $\mathbf{0 . 0 1 1}$ \\
\hline
\end{tabular}

Durum 6 için, $x=290$ ve $390 \mathrm{~cm}$ için 10 farklı yükseklikte hesaplanan GCI değerleri sirasıyla Tablo 5 ve 6'da verilmiştir. Buna göre, çok daha düşük bir derinliğe sahip olan bu akım için GCI değerleri $\mathrm{x}=290 \mathrm{~cm}$ 'de $\% 1.972$ değerine ulaşırken, en düşük değer \%0.1 olmuştur. Burada da Durum 1'e benzer sonuçlar elde edilmiştir. Bunun yanında, $\mathrm{x}=390 \mathrm{~cm}$ 'de akım tamamen gelişip düzenli üniform bir akım durumuna geçtiği, tipik bir açık kanal akımına dönüştüğünden GCI değerlerinin oldukça düşük değerlerde olduğu görülmüştür. Elde edilen tüm değerlerin \%2'den küçük olduğu görülmektedir. Dolasılyla hesaplamalarda A $\breve{g} 3$ yapısının kullanılmasi durumunda, hesaplama ağının sayısal model sonuçlar üzerinde etkisinin olmadığı söylenebilir.

Tablo 5. Durum 6 için $x=290$ cm'deki GCI sonuçları

\begin{tabular}{|c|c|c|c|c|c|c|c|c|c|c|}
\hline $\mathbf{n}(\mathbf{m m})$ & $\mathbf{d}_{\mathbf{1}}(\mathbf{m m})$ & $\mathbf{d}_{\mathbf{2}}(\mathbf{m m})$ & $\mathbf{d}_{\mathbf{3}}(\mathbf{m m})$ & $\mathbf{U}_{\mathbf{s} 1}$ & $\mathbf{U}_{\mathbf{s} 2}$ & $\mathbf{U}_{\mathbf{s} 3}$ & $\mathbf{r}_{\mathbf{1}}$ & $\mathbf{r}_{\mathbf{2}}$ & $\mathbf{p}$ & $\mathbf{G C I}$ \\
\hline $\mathbf{2 . 5}$ & 1.414 & 1.171 & 0.928 & 0.106 & 0.103 & 0.108 & 1.208 & 1.262 & -1.374 & $\mathbf{- 0 . 2 2 4}$ \\
\hline $\mathbf{5}$ & 1.581 & 1.308 & 1.049 & 0.132 & 0.127 & 0.132 & 1.209 & 1.246 & -0.012 & $\mathbf{- 1 . 9 7 2}$ \\
\hline $\mathbf{7 . 5}$ & 1.779 & 1.429 & 1.125 & 0.144 & 0.138 & 0.145 & 1.245 & 1.270 & 0.320 & $\mathbf{0 . 6 9 6}$ \\
\hline $\mathbf{1 0}$ & 1.870 & 1.490 & 1.201 & 0.153 & 0.146 & 0.153 & 1.255 & 1.241 & -0.174 & $\mathbf{- 1 . 4 8 8}$ \\
\hline $\mathbf{1 5}$ & 1.992 & 1.627 & 1.292 & 0.159 & 0.152 & 0.159 & 1.224 & 1.259 & 0.793 & $\mathbf{0 . 2 8 3}$ \\
\hline $\mathbf{1 7 . 5}$ & 2.372 & 1.885 & 1.490 & 0.169 & 0.161 & 0.169 & 1.258 & 1.265 & 0.491 & $\mathbf{0 . 4 6 7}$ \\
\hline $\mathbf{2 2 . 5}$ & 2.646 & 2.053 & 1.673 & 0.177 & 0.168 & 0.176 & 1.289 & 1.227 & -0.480 & $\mathbf{- 0 . 6 0 2}$ \\
\hline $\mathbf{2 7 . 5}$ & 2.494 & 1.773 & 1.673 & 0.183 & 0.174 & 0.182 & 1.407 & 1.060 & -11.080 & $\mathbf{- 0 . 1 1 7}$ \\
\hline $\mathbf{3 5}$ & 2.494 & 2.007 & 1.673 & 0.189 & 0.181 & 0.189 & 1.242 & 1.200 & -0.953 & $\mathbf{- 0 . 3 1 8}$ \\
\hline $\mathbf{4 5}$ & 2.494 & 1.667 & 1.657 & 0.194 & 0.188 & 0.196 & 1.496 & 1.006 & -18.330 & $\mathbf{- 0 . 0 8 2}$ \\
\hline
\end{tabular}

Tablo 6. Durum 6 için $x=390 \mathrm{~cm}$ 'deki GCI sonuçları

\begin{tabular}{|c|c|c|c|c|c|c|c|c|c|c|}
\hline $\mathbf{n}(\mathbf{m m})$ & $\mathbf{d}_{\mathbf{1}}(\mathbf{m m})$ & $\mathbf{d}_{\mathbf{2}}(\mathbf{m m})$ & $\mathbf{d}_{\mathbf{3}}(\mathbf{m m})$ & $\mathbf{U}_{\mathbf{s 1}}$ & $\mathbf{U}_{\mathbf{s} 2}$ & $\mathbf{U}_{\mathbf{s} 3}$ & $\mathbf{r}_{\mathbf{1}}$ & $\mathbf{r}_{\mathbf{2}}$ & $\mathbf{p}$ & $\mathbf{G C I}$ \\
\hline $\mathbf{2 . 5}$ & 1.417 & 1.179 & 0.931 & 0.108 & 0.108 & 0.112 & 1.202 & 1.267 & -16.777 & $\mathbf{- 0 . 0 5 0}$ \\
\hline $\mathbf{5}$ & 1.580 & 1.298 & 1.039 & 0.133 & 0.133 & 0.137 & 1.217 & 1.250 & -9.240 & $\mathbf{- 0 . 0 4 2}$ \\
\hline $\mathbf{7 . 5}$ & 1.774 & 1.428 & 1.114 & 0.146 & 0.145 & 0.150 & 1.242 & 1.282 & -6.463 & $\mathbf{- 0 . 0 4 4}$ \\
\hline $\mathbf{1 0}$ & 1.883 & 1.493 & 1.201 & 0.155 & 0.153 & 0.158 & 1.261 & 1.243 & -6.318 & $\mathbf{- 0 . 0 4 8}$ \\
\hline $\mathbf{1 5}$ & 1.991 & 1.634 & 1.298 & 0.161 & 0.159 & 0.164 & 1.219 & 1.258 & -4.106 & $\mathbf{- 0 . 0 6 1}$ \\
\hline $\mathbf{1 7 . 5}$ & 2.370 & 1.883 & 1.493 & 0.171 & 0.168 & 0.174 & 1.259 & 1.261 & -3.042 & $\mathbf{- 0 . 0 7 7}$ \\
\hline $\mathbf{2 2 . 5}$ & 2.651 & 2.056 & 1.666 & 0.178 & 0.175 & 0.180 & 1.289 & 1.234 & -3.129 & $\mathbf{- 0 . 0 8 3}$ \\
\hline $\mathbf{2 7 . 5}$ & 2.499 & 1.668 & 1.666 & 0.183 & 0.180 & 0.186 & 1.498 & 1.001 & -79.824 & $\mathbf{- 0 . 0 6 7}$ \\
\hline $\mathbf{3 5}$ & 2.499 & 2.002 & 1.666 & 0.189 & 0.185 & 0.192 & 1.249 & 1.201 & -3.217 & $\mathbf{- 0 . 0 9 3}$ \\
\hline $\mathbf{4 5}$ & 2.499 & 1.669 & 1.666 & 0.194 & 0.191 & 0.197 & 1.497 & 1.002 & -57.475 & $\mathbf{- 0 . 0 6 1}$ \\
\hline
\end{tabular}


Ayrıca, iki farklı debi ile farklı kesitlerde ve farklı yüksekliklerde elde edilen GCI değerleri incelendiğinde, hesaplanan büyük GCI değerlerinin akımın ani değişimler sergilediği katı sınıra yakın olan bölgelerde olduğu ve tabandan itibaren yapılacak sıklaştırmaların çözüm üzerine olumlu etkiler sağlayacağı değerlendirilmiştir.

\section{4. Çözüm bölgesi, başlangıç ve sınır şartları}

Sayısal modellemede kullanılan çözüm bölgesi, sınır ve başlangıç şartları Şekil 3'te verilmiştir.
Buna göre, kanal tabanında sıfır hız sınır şartı (noslip stationary wall condition- $\mathrm{u}=0, \mathrm{v}=0$ ), giriş sınırının hemen üstünde, kanal üst ve çıkış sınırında $\mathrm{p}=0$ (pressure outlet), giriş sınırında (velocity inlet) $v=0$ alınmış ve $u$ hızı ise her bir durum için deneysel verilerden hesaplanarak tanımlanmıştır. Kanal sonunda çıkış su derinliğine bağlı olarak açık kanal çözümü yapılmış ve her bir deneyin çıkış su derinliği ayrı ayrı tanımlanmıştır. Sayısal modellemelerde başlangıç şartı olarak çözüm bölgesi tamamen boş $(\mathrm{F}=0)$, sadece giriş sinırında $\mathrm{F}=1$ olarak tanımlanmıştır.

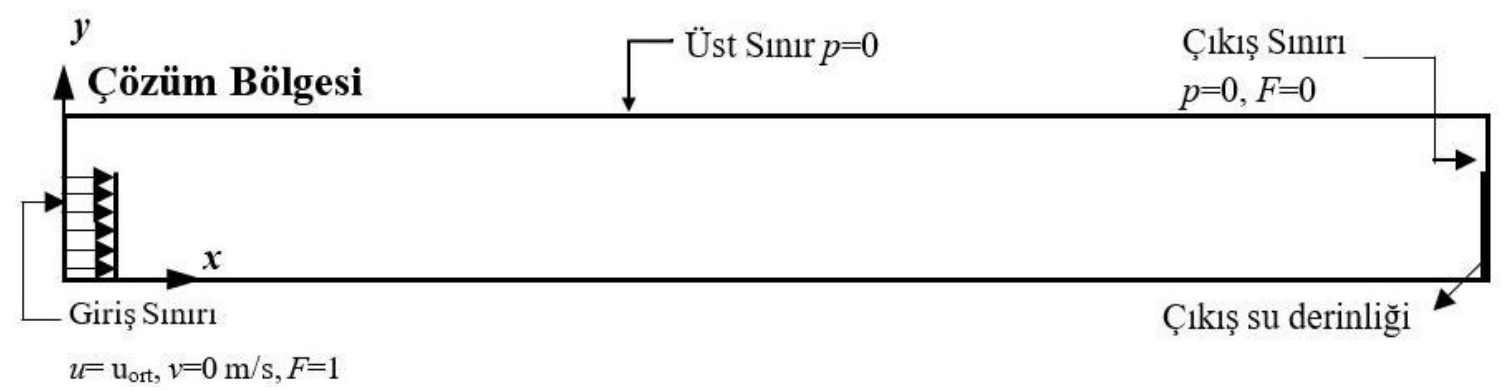

Şekil 3. Sayısal çözüm bölgesi ve sınır şartlar

\section{Bulgular ve tartışmalar}

\subsection{Deneysel ve saylsal hiz profilleri}

Deneysel ve farklı türbülans modelleri kullanılarak elde edilen sayısal hiz profillerinin karşılaştırılmasında niceliksel kriter olarak Ortalama Karesel Hata (OKH) ve Ortalama Mutlak Göreceli Hata (OMGH) parametreleri kullanılmıştır. OKH ve OMGH değerleri sırasıyla Denklem 8 ve 9'da verildiği gibi hesaplanmaktadır.

$$
\begin{aligned}
& O K H=\frac{1}{N} \sum_{n=1}^{N}\left(u_{d}-u_{h}\right) \\
& O M G H=\frac{1}{N} \sum_{n=1}^{N}\left(\frac{u_{d}-u_{h}}{u_{d}}\right)
\end{aligned}
$$

Burada, $u_{d}$ ve $u_{h}$ sirasiyla deneysel ve sayisal hiz değerini, $\mathrm{N}$ ise hız profilindeki nokta sayısını ifade etmektedir.
Tablo 7'de, Durum 1 için farklı türbülans modelleri ile elde edilen $\mathrm{OKH}$ ve $\mathrm{OMGH}$ değerleri verilmiştir. Tablo da en başarılı olan model sonuçları koyu yazılmış ve modellerin başarı sıralaması parantez içerisinde üstel olarak verilmiştir. Tablodaki değerlere göre, kanal başlangıcında ( $\mathrm{x}=0.6-2.4 \mathrm{~m})$ SST modeli en başarılı model olurken, kanal ortasında (2.9 ve 3.4 $\mathrm{m})$ ise DES modeli deneysel verilere diğer modellere kıyasla daha fazla yakınsamıştır. Kanal sonuna doğru $(x=3.9-5.4 \mathrm{~m})$ ise yine SST modelinin deneysel verilere yakın tahminde bulunduğu görülmüştür. Tablonun son satırında verilen tüm kanal boyunca ele alınan kesitlerde elde edilen $\mathrm{OKH}$ ve $\mathrm{OMGH}$ değerlerinin ortalamaları değerlendirildiğinde, kullanılan türbülans modellerinin başarı sıralaması SST, DES, RNG ve RSM şeklinde olmuştur. OKH değerlerine göre, ele alınan 10 kesitten 6'sında SST modeli, $\mathrm{x}=2.9$ ve $3.4 \mathrm{~m}$ kesitlerinde ise DES daha başarılı olmuştur. Ancak, SST ve DES modelleriyle elde edilen $\mathrm{OKH}$ değerleri arasındaki farkın da oldukça küçük olduğu belirlenmiştir. 
Tablo 7. Durum 1 için farklı türbülans modellerine göre $\mathrm{OKH}\left(\mathrm{cm}^{2} / \mathrm{s}^{2}\right)$ ve $\mathrm{OMGH}(\%)$ değerleri

\begin{tabular}{|c|c|c|c|c|c|c|c|c|}
\hline \multirow[b]{2}{*}{$\mathbf{x}(\mathbf{m})$} & \multicolumn{2}{|c|}{ RNG } & \multicolumn{2}{|c|}{ SST } & \multicolumn{2}{|c|}{ RSM } & \multicolumn{2}{|c|}{ DES } \\
\hline & OKH & OMGH & OKH & OMGH & OKH & OMGH & OKH & OMGH \\
\hline 0.6 & $6.60(3)$ & $6.78(3)$ & 5.91(1) & $6.41(2)$ & $6.15(2)$ & $6.36(1)$ & $9.13(4)$ & $8.04(4)$ \\
\hline 1.4 & $6.26(4)$ & $5.69(3)$ & $5.33(1)$ & $5.51(2)$ & $5.97(2)$ & $5.26(1)$ & $6.00(3)$ & $6.16(4)$ \\
\hline 1.9 & 7.54(3) & $6.35(3)$ & $6.40(1)$ & $6.03(1)$ & $7.58(4)$ & $6.14(2)$ & $6.78(2)$ & $6.47(4)$ \\
\hline 2.4 & $7.98(3)$ & $6.81(4)$ & 5.64(1) & $5.78(1)$ & $8.89(4)$ & $6.72(3)$ & $6.68(2)$ & $6.57(2)$ \\
\hline 2.9 & $7.67(3)$ & $5.88(3)$ & $5.12(2)$ & $4.95(2)$ & $9.58(4)$ & $6.18(4)$ & 4.37(1) & $4.86(1)$ \\
\hline 3.4 & $6.99(3)$ & 5.78(3) & $4.57(2)$ & $4.70(1)$ & $9.13(4)$ & $6.40(4)$ & $4.23(1)$ & $4.96(2)$ \\
\hline 3.9 & $5.73(3)$ & $5.56(2)$ & 3.48(1) & $3.96(1)$ & $7.87(4)$ & $6.28(4)$ & $5.13(2)$ & $5.63(3)$ \\
\hline 4.4 & $6.08(3)$ & $6.02(3)$ & 3.87(1) & $4.55(1)$ & $8.50(4)$ & $6.79(4)$ & $4.63(2)$ & $5.52(2)$ \\
\hline 4.9 & $6.96(2)$ & $5.96(2)$ & 5.24(1) & $5.03(1)$ & $8.19(4)$ & $6.33(3)$ & $7.57(3)$ & $6.78(4)$ \\
\hline 5.4 & $5.38(2)$ & $5.69(3)$ & 5.37(1) & $5.62(2)$ & $5.39(3)$ & $5.51(1)$ & $8.43(4)$ & $7.26(4)$ \\
\hline Ort. & $6.72(3)$ & $6.05(2)$ & $5.09(1)$ & $5.25(1)$ & 7.73(4) & $6.20(3)$ & $6.30(2)$ & $6.23(4)$ \\
\hline
\end{tabular}

Durum 1 için kanal boyunca ele alınan kesitlerde elde edilen OKH ve OMGH değerinin ortalamasına göre deneysel hiz profillerine en yakın tahminde bulunan SST modeli ile elde edilen sayisal hiz profillerinin deneysel sonuçlar ile karşılaştırılması Şekil 4'te verilmiştir. Verilen grafikler incelendiğinde, SST modelinin kanal boyunca ele alınan kesitlerde deneysel verilere yakın sonuçlar verdiği, ancak katı sınıra yakın olan bölgede deneysel verilerden uzaklaştı̆̆ ve genel olarak deneysel verilerden daha küçük bir hız değeri tahmin ettiği görülmüştür. $\mathrm{Su}$ yüzüne yakın bölgede, kanal tabanına yakın bölgeye kıyasla sayısal modelleme sonuçlarının deneysel profile daha fazla yakınsadığı görülmektedir. Ayrıca, sayısal ve deneysel sinır tabakası kalınlıklarının birbirinden farklılık gösterdiği ifade edilebilir.
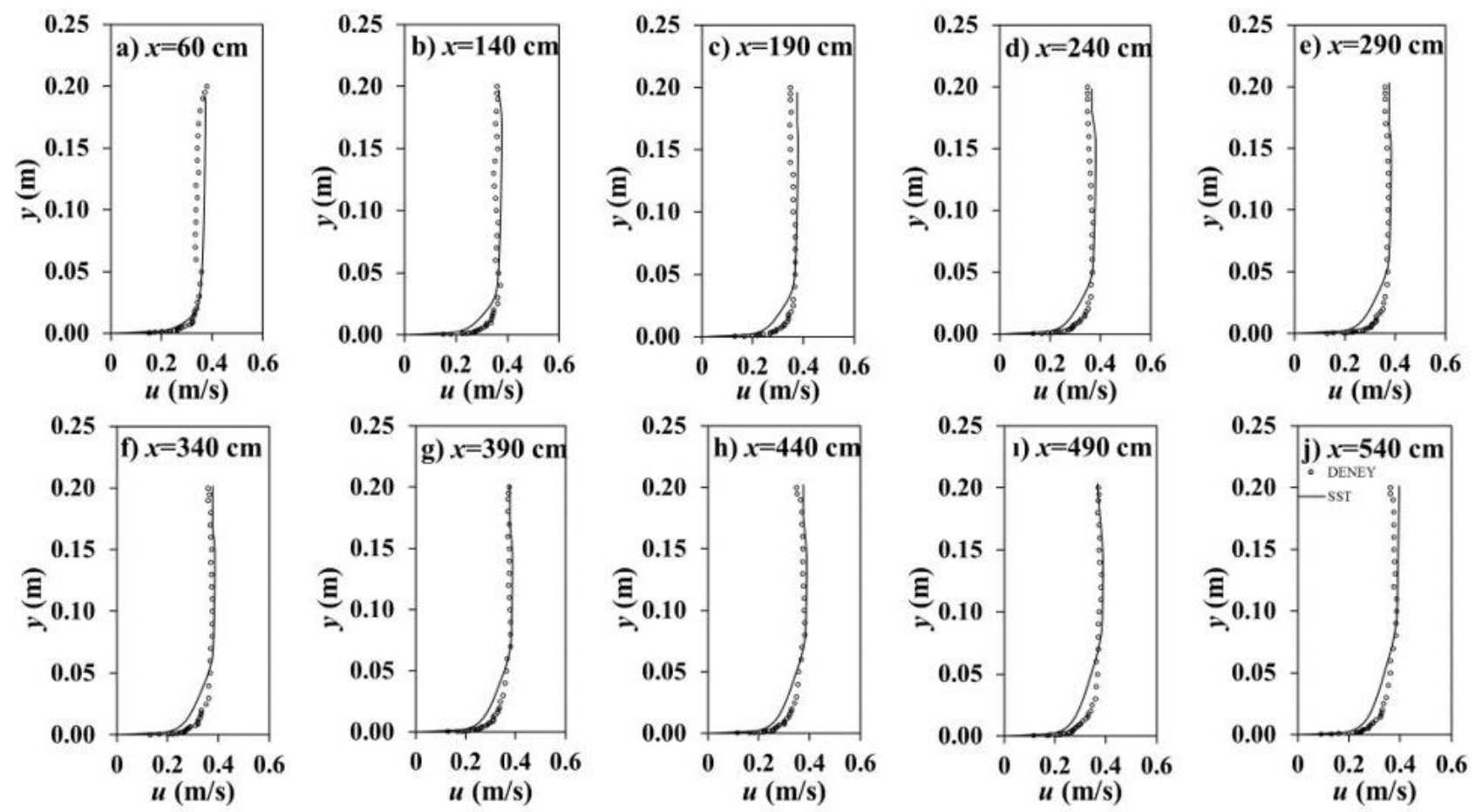

Şekil 4. Durum 1 için deneysel ve sayısal hız profilleri

Tablo 8'de, Durum 2 için farklı türbülans modelleri ile elde edilen $\mathrm{OKH}$ ve $\mathrm{OMGH}$ değerleri verilmiştir. $\mathrm{OKH}$ kriterine göre $\mathrm{x}=0.6,1.9,2.4,2.9$, 3.4 ve 3.9 m kesitlerinde DES modeli, 1.4 ve $4.4 \mathrm{~m}$ kesitlerinde RSM modeli, 4.9 ve 5.4 m kesitlerinde ise RNG türbülans modeli en başarılı olmuştur.
OMGH kriterine göre ise $\mathrm{x}=0.6,1.9,2.4$ ve $2.9 \mathrm{~m}$ kesitlerinde DES modeli OKH kriterine benzer olarak başarılı olurken, $\mathrm{x}=3.4,3.9$ ve $4.9 \mathrm{~m}$ kesitlerinde ise OMGH kriterine göre SST türbülans modeli en başarılı olmuştur. Ayrıca, $5.4 \mathrm{~m}$ kesitinde $\mathrm{OKH}$ kriterinde olduğu gibi RNG 
türbülans modeli deneysel verilere daha yakın tahminde bulunmuştur. Ortalama değerlere göre, en küçük OKH ve OMGH değeri, DES modelinde elde edilmiştir. Yani diğer bir ifadeyle DES modeli kullanılarak gerçekleştirilen sayısal model sonucunda deneysel verilere en yakın tahminde bulunmuştur. Türbülans modellerinin başarı sıralamas1 DES, SST, RNG ve RSM şeklinde oluşmuştur. $\mathrm{Bu}$ sonuçtan ikincil akımlarda ve akımda ayrılmaların olduğu akım durumlarında başarılı sonuçlar verdiği bilinen RSM modelinin en başarısız model olduğu görülmektedir. Ele alınan akım durumunda ayrılmanın ve ikincil akımların oluşmamasının bu sonuca neden olduğu söylenebilir. Katı sınıra yakın bölgede k- $\varepsilon$ denklemlerini çözen, katı sınırdan uzaklaştıkça k$\omega$ denklemlerini çözmesinden dolayı hibrit bir model olan SST modelinin, tüm akım derinliği boyunca k- $\varepsilon$ denklemini çözen RNG modeline üstünlük sağladığg görülmektedir.

Tablo 8. Durum 2 için farklı türbülans modellerine göre $\mathrm{OKH}\left(\mathrm{cm}^{2} / \mathrm{s}^{2}\right)$ ve $\mathrm{OMGH}(\%)$ değerleri

\begin{tabular}{|c|c|c|c|c|c|c|c|c|}
\hline \multirow{2}{*}{$\mathbf{x}(\mathbf{m})$} & \multicolumn{2}{|c|}{ RNG } & \multicolumn{2}{|c|}{ SST } & \multicolumn{2}{|c|}{ RSM } & \multicolumn{2}{|c|}{ DES } \\
\hline & $\overline{\mathrm{OKH}}$ & OMGH & OKH & OMGH & OKH & OMGH & OKH & OMGH \\
\hline 0.6 & $38.87^{(3)}$ & $8.74^{(3)}$ & $31.19^{(2)}$ & $7.30^{(2)}$ & $67.43^{(4)}$ & $10.55^{(4)}$ & $22.67^{(1)}$ & $6.77^{(1)}$ \\
\hline 1.4 & $57.26^{(3)}$ & $10.01^{(4)}$ & $58.01^{(4)}$ & $9.69^{(3)}$ & $7.25^{(1)}$ & $3.58^{(1)}$ & $30.49^{(2)}$ & $7.81^{(2)}$ \\
\hline 1.9 & $315.00^{(3)}$ & $7.55^{(3)}$ & $304.74^{(2)}$ & $6.84^{(2)}$ & $345.19^{(4)}$ & $11.12^{(4)}$ & $287.79^{(1)}$ & $4.95^{(1)}$ \\
\hline 2.4 & $14.64^{(2)}$ & $4.40^{(2)}$ & $26.73^{(4)}$ & $5.61^{(4)}$ & $16.17^{(3)}$ & $4.48^{(3)}$ & $4.18^{(1)}$ & $2.71^{(1)}$ \\
\hline 2.9 & $34.39^{(2)}$ & $6.31^{(2)}$ & $40.95^{(3)}$ & $7.30^{(3)}$ & $127.28^{(4)}$ & $15.90^{(4)}$ & $15.39^{(1)}$ & $5.15^{(1)}$ \\
\hline 3.4 & $26.27^{(3)}$ & $5.89^{(3)}$ & $18.65^{(2)}$ & $4.86^{(1)}$ & $57.59^{(4)}$ & $10.58^{(4)}$ & $15.81^{(1)}$ & $5.27^{(2)}$ \\
\hline 3.9 & $17.14^{(3)}$ & $4.48^{(2)}$ & $15.37^{(2)}$ & $4.12^{(1)}$ & $37.73^{(4)}$ & $8.75^{(4)}$ & $14.67^{(1)}$ & $5.35^{(3)}$ \\
\hline 4.4 & $10.70^{(4)}$ & $3.55^{(2)}$ & $9.72^{(3)}$ & $3.83^{(3)}$ & $4.58^{(1)}$ & $2.56^{(1)}$ & $8.89^{(2)}$ & $4.09^{(4)}$ \\
\hline 4.9 & $5.44^{(1)}$ & $3.17^{(2)}$ & $6.77^{(2)}$ & $2.81^{(1)}$ & $32.06^{(4)}$ & $8.44^{(4)}$ & $9.23^{(3)}$ & $4.13^{(3)}$ \\
\hline 5.4 & $5.11^{(1)}$ & $2.57^{(1)}$ & $5.66^{(2)}$ & $3.05^{(2)}$ & $7.48^{(3)}$ & $3.36^{(3)}$ & $11.24^{(4)}$ & $4.67^{(4)}$ \\
\hline Ort. & $52.48^{(3)}$ & $5.67^{(3)}$ & $51.78^{(2)}$ & $5.54^{(2)}$ & $70.28^{(4)}$ & $7.93^{(4)}$ & $42.04^{(1)}$ & $5.09^{(1)}$ \\
\hline
\end{tabular}

Durum 2 için kanal boyunca ortalama OKH ve OMGH değerlerine göre hız alanını kullanılan diğer modellere kıyasla daha başarılı modellediği görülen DES modeli ile elde edilen sayısal hız profillerinin deneysel profillerle karşılaştırılması Şekil 5'te verilmiştir. DES modelinin $\mathrm{x}=60$ ve 140 cm kesitlerinde katı sınıra yakın bölgede ve akım derinliği boyunca deneysel verilerden uzak tahminde bulunmasının yanında hız profilinin genel olarak gidişatının benzer olduğu görülmektedir. Kanal boyunca ele alınan diğer kesitlerde, $x=60$ ve $140 \mathrm{~cm}$ kesitlerine klyasla deneysel verilere daha fazla yakınsamıştır. Durum 2 için DES modeli kullanılarak elde edilen hız profillerinin Durum 1'e kıyasla katı sınıra yakın bölgede deneysel verilerle daha uyumlu olduğu söylenebilir. Aksine, tam türbülanslı bölgede ise deneysel ve sayısal hiz profillerinin uyumu kanal eğiminin artmasıyla azalmaktadır. $\mathrm{Bu}$ bölgede Durum 1'de elde edilen sayısal hiz profilleri deneysel sonuçlara Durum 2'ye kıyasla daha fazla yakınsamışıtır. 

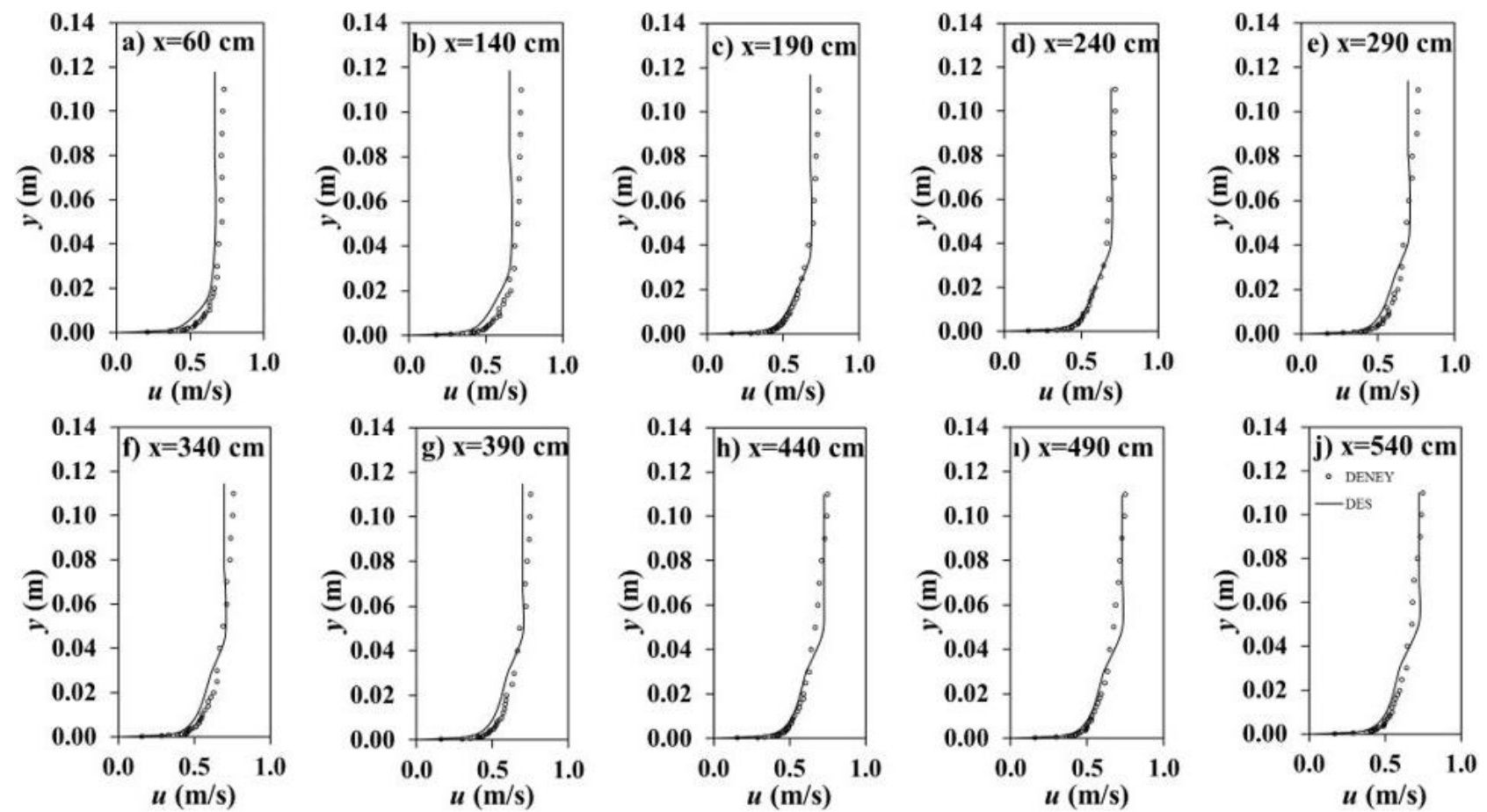

Şekil 5. Durum 2 için deneysel ve sayısal hız profilleri

Durum 3 için farklı türbülans modelleri ile elde edilen $\mathrm{OKH}$ ve $\mathrm{OMGH}$ değerleri Tablo 9'da verilmiştir. Buna göre, OKH değerleri kanal girişinde ( $\mathrm{x}=0.6$ ve $2.4 \mathrm{~m}$ ) DES modeli başarılı olurken, bu kesitler haricindeki ele alınan diğer tüm kesitlerde ise RSM modeli en başarılı model olmuştur. OMGH değerlerine bakıldığında ise kanal başlangıcında DES modeli RSM modelinden daha başarılı olmuştur. DES modeli ile RNG modelinin sonuçlarının birbirine daha yakın olduğu görülmektedir. Tüm kanal boyunca elde edilen $\mathrm{OKH}$ ve $\mathrm{OMGH}$ değerlerinin ortalamaları değerlendirildiğinde, kullanılan türbülans modellerinin başarı sıralaması RSM, RNG, DES ve SST şeklinde olmuştur. OKH değerlerine göre, ele alınan 10 kesitin 8 kesitinde RSM modeli başarılı olmuş, RNG, RSM, DES modellerinin sonuçlarının arasındaki farkın küçük olmuş ve SST türbülans modeli sonucunda elde edilen $\mathrm{OKH}$ ve OMGH değerlerinin büyük olması, bu modelin diğer modellere göre hata değerlerinin daha büyük olduğunu ifade etmektedir. Bu sonuçtan, SST modelinin Durum 3 için deneysel verileri tahmin etmekte başarısız olduğu söylenebilir.

Tablo 9. Durum 3 için farklı türbülans modellerine göre $\mathrm{OKH}\left(\mathrm{cm}^{2} / \mathrm{s}^{2}\right)$ ve $\mathrm{OMGH}(\%)$ değerleri

\begin{tabular}{|c|l|l|l|l|l|l|l|l|}
\hline \multirow{2}{*}{ x (m) } & \multicolumn{2}{|c|}{ RNG } & \multicolumn{2}{c|}{ SST } & \multicolumn{2}{c|}{ RSM } & \multicolumn{2}{c|}{ DES } \\
\cline { 2 - 8 } & OKH & OMGH & OKH & OMGH & OKH & OMGH & OKH & OMGH \\
\hline $\mathbf{0 . 6}$ & $2.98^{(3)}$ & $4.03^{(4)}$ & $3.23^{(4)}$ & $3.82^{(3)}$ & $2.68^{(2)}$ & $3.79^{(2)}$ & $\mathbf{2 . 4 7 ^ { ( \mathbf { 1 } }}$ & $\mathbf{3 . 5 9}^{(\mathbf{1})}$ \\
\hline $\mathbf{1 . 4}$ & $2.49^{(3)}$ & $3.63^{(4)}$ & $2.77^{(4)}$ & $3.37^{(3)}$ & $\mathbf{2 . 1 6}^{(\mathbf{1})}$ & $3.14^{(2)}$ & $2.35^{(2)}$ & $\mathbf{2 . 6 8}^{(\mathbf{1})}$ \\
\hline $\mathbf{1 . 9}$ & $3.72^{(3)}$ & $4.96^{(4)}$ & $4.10^{(4)}$ & $4.35^{(2)}$ & $\mathbf{3 . 3 4}^{(\mathbf{1})}$ & $4.44^{(3)}$ & $3.66^{(2)}$ & $\mathbf{3 . 8 4}^{(\mathbf{1})}$ \\
\hline $\mathbf{2 . 4}$ & $3.44^{(3)}$ & $5.12^{(4)}$ & $3.66^{(4)}$ & $4.82^{(3)}$ & $3.20^{(2)}$ & $4.80^{(2)}$ & $\mathbf{2 . 7 9 ^ { ( \mathbf { 1 } }}$ & $\mathbf{3 . 9 4}^{(\mathbf{1})}$ \\
\hline $\mathbf{2 . 9}$ & $6.11^{(2)}$ & $6.53^{(3)}$ & $9.27^{(4)}$ & $7.13^{(4)}$ & $\mathbf{5 . 5 7}^{(\mathbf{1})}$ & $6.01^{(2)}$ & $6.43^{(3)}$ & $\mathbf{5 . 5 9}^{(\mathbf{1})}$ \\
\hline $\mathbf{3 . 4}$ & $4.52^{(2)}$ & $5.59^{(3)}$ & $9.65^{(4)}$ & $7.74^{(4)}$ & $\mathbf{4 . 0 3}^{(\mathbf{1})}$ & $\mathbf{4 . 8 6}^{(\mathbf{1})}$ & $5.20^{(3)}$ & $4.91^{(2)}$ \\
\hline $\mathbf{3 . 9}$ & $5.41^{(2)}$ & $6.23^{(3)}$ & $10.25^{(4)}$ & $8.10^{(4)}$ & $\mathbf{4 . 8 1}^{(\mathbf{1})}$ & $5.45^{(2)}$ & $5.59^{(3)}$ & $\mathbf{5 . 3 5}^{(\mathbf{1})}$ \\
\hline $\mathbf{4 . 4}$ & $5.88^{(3)}$ & $6.61^{(3)}$ & $11.59^{(4)}$ & $8.87^{(4)}$ & $\mathbf{4 . 8 7}^{(\mathbf{1})}$ & $5.77^{(2)}$ & $5.64^{(2)}$ & $\mathbf{5 . 6 5}^{(\mathbf{1})}$ \\
\hline $\mathbf{4 . 9}$ & $5.48^{(2)}$ & $6.40^{(2)}$ & $10.84^{(4)}$ & $8.60^{(4)}$ & $\mathbf{4 . 9 0}^{(\mathbf{1})}$ & $\mathbf{5 . 6 5}^{(\mathbf{1})}$ & $6.46^{(3)}$ & $6.40^{(3)}$ \\
\hline $\mathbf{5 . 4}$ & $6.45^{(2)}$ & $6.63^{(3)}$ & $11.49^{(4)}$ & $8.62^{(4)}$ & $\mathbf{5 . 4 8}^{(\mathbf{1})}$ & $\mathbf{5 . 9}^{(\mathbf{1})}$ & $7.70^{(3)}$ & $6.54^{(2)}$ \\
\hline Ort. & $4.65^{(2)}$ & $5.57^{(3)}$ & $7.69^{(4)}$ & $6.54^{(4)}$ & $\mathbf{4 . 1 0}^{(\mathbf{1})}$ & $4.98^{(2)}$ & $4.83^{(3)}$ & $\mathbf{4 . 8 5}^{(\mathbf{1})}$ \\
\hline
\end{tabular}

Durum 3 için ortalama $\mathrm{OKH}$ ve $\mathrm{OMGH}$ değerlerine göre kanal boyunca hız alanını kullanılan diğer modellere kıyasla RSM modeli daha başarılı modellemiştir. $\mathrm{Bu}$ model ile elde edilen sayısal hız profillerinin deneysel sonuçlar ile karşılaştırılması Şekil 6'da verilmiştir. Grafikler 
incelendiğinde, RSM modelinin $\mathrm{x}=60$ ve $240 \mathrm{~cm}$ kesitlerinde katı sınıra yakın bölgede deneysel sonuçlara yakın tahminde bulunurken, katı sınırının akım alanı üzerinde etkisinin olmadığı, bölgede akım derinliği boyunca deneysel verilerden uzak tahminde bulunduğu görülmektedir. $\mathrm{x}=60$ ve $240 \mathrm{~cm}$ kesitleri dışında kalan tüm kesitlerde ise akım derinliği boyunca deneysel verilere yakın tahminde bulunduğu görülmektedir. Tablo 9'da verilen $\mathrm{OKH}$ ve $\mathrm{OMGH}$ değerlerine göre, RSM modeli Durum 3 ve 4 dışında kullanılan diğer modellere göre deneysel sonuçlardan daha kötü tahminde bulunduğu görülmüştür. Kanal girişinde deneysel hız profilleriyle sayisal model sonucunun uyumu gözlenirken, kanalın sonlarına doğru uyum gittikçe azalmıştır. RSM türbülans modeli kanal tabanında yani katı sınırına yakın bölgede akım hız alanlarını deneysel verilere göre daha düşük tahmin ederken, katı sınırın etkisi dışında kalan bölgede akım derinliği boyunca deneysel sonuçlara daha yakın tahminde bulunmuştur. $\mathrm{OKH}$ ve $\mathrm{OMGH}$ değeri incelendiğinde en yakın tahmini $\mathrm{x}=190 \mathrm{~cm}$ kesitinde elde ederken, en uzak tahmini de $x=290$ $\mathrm{cm}$ kesitinde gerçekleşmiştir.
Tablo 10'da, Durum 4 için farklı türbülans modelleri ile elde edilen $\mathrm{OKH}$ ve OMGH değerleri verilmiştir. Tabloya göre ele alınan tüm kanal kesitlerinde en küçük OKH ile OMGH değerlerinin DES modeliyle elde edilmesi, DES türbülans modelinin en başarılı model olduğunu belirtmektedir. Tablodan, SST ve RSM modellerine ait $\mathrm{OKH}$ ve $\mathrm{OMGH}$ değerleri incelendiğinde birbirine yakın olduğu görülmekte, bu akım durumu için SST ve RSM modellerinin birbirine benzer tahminde bulunduğunu göstermektedir. RNG modelinin $\mathrm{OKH}$ ve $\mathrm{OMGH}$ değerlerinin kullanılan diğer üç modele kıyasla çok büyük olması başarısız olduğunu göstermektedir. SST modeli, kanal girişinde $\mathrm{x}=2 \mathrm{~m}$ kesitine kadar oldukça iyi tahminde bulunurken, $\mathrm{x}=2 \mathrm{~m}$ kesitinden sonra SST türbülans modeliyle elde edilen hiz profillerinin, deneysel profillerden uzaklaştığ 1 anlaşılmaktadır. Kanal boyunca 10 farklı kesitte elde edilen OKH ve OMGH ortalama değerlerine göre, en küçük OKH ve OMGH değeri DES modelinde elde edilmiștir. Türbülans modellerinin başarı sıralaması DES, RSM, SST, ve RNG şeklinde oluşmuştur.
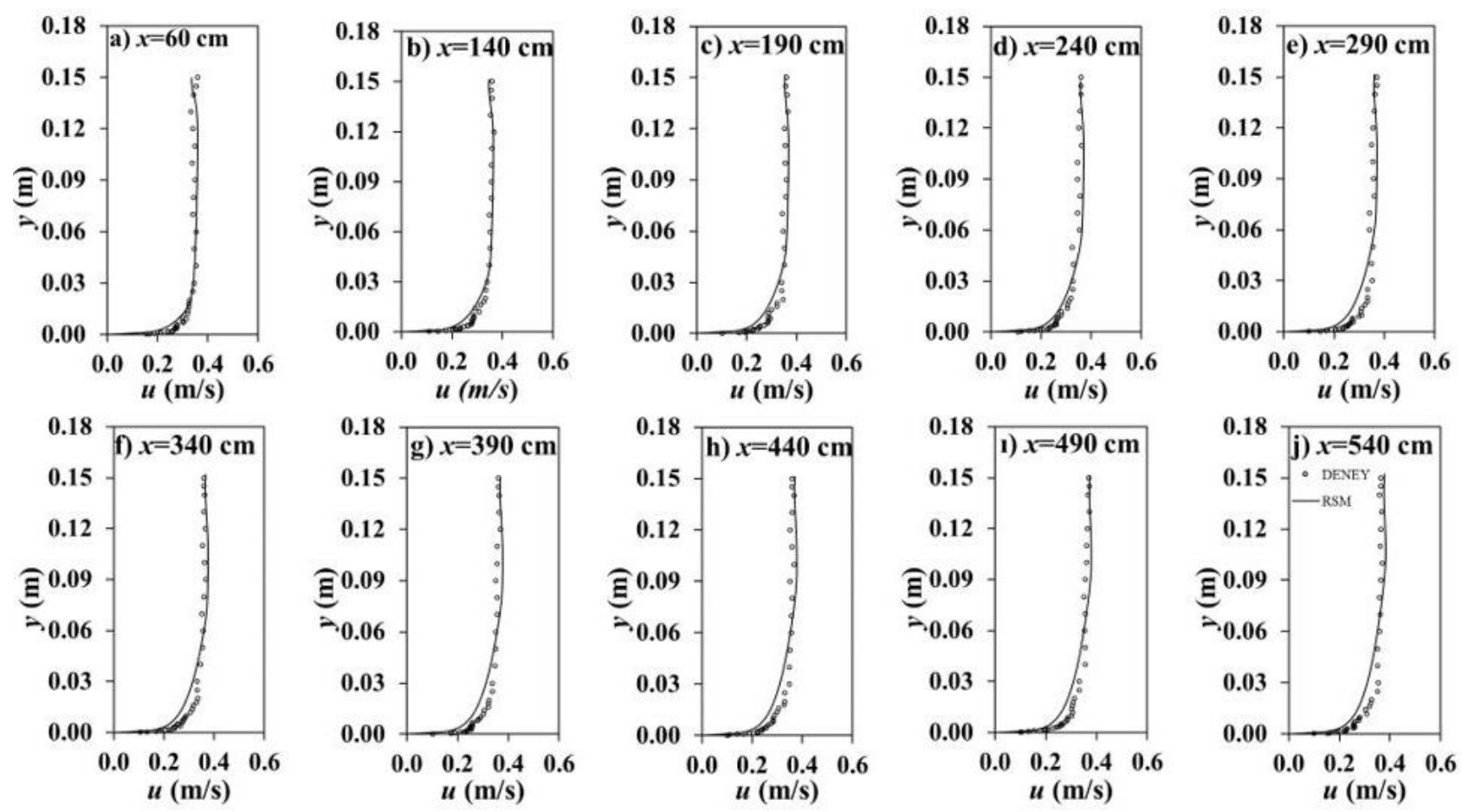

Şekil 6. Durum 3 için deneysel ve sayısal hız profilleri 
Tablo 10. Durum 4 için farklı türbülans modellerine göre OKH $\left(\mathbf{c m}^{2} / \mathbf{s}^{2}\right)$ ve OMGH (\%) değerleri

\begin{tabular}{|c|c|c|c|c|c|c|c|c|}
\hline \multirow{2}{*}{$\mathbf{x}(\mathbf{m})$} & \multicolumn{2}{|c|}{ RNG } & \multicolumn{2}{|c|}{ SST } & \multicolumn{2}{|c|}{ RSM } & \multicolumn{2}{|c|}{ DES } \\
\hline & OKH & OMGH & OKH & OMGH & OKH & OMGH & OKH & OMGH \\
\hline 0.6 & $43.58^{(4)}$ & $.95^{(4)}$ & $6.80^{(2)}$ & $6.11^{(2)}$ & $12.17^{(3)}$ & $8.00^{(3)}$ & $2.85^{(1)}$ & $3.86^{(1)}$ \\
\hline 1.4 & $.45^{(4)}$ & $11.01^{(4)}$ & $3.59^{(2)}$ & $33^{(2)}$ & $15.60^{(3)}$ & $10.86^{(3)}$ & $1.50^{(1)}$ & $2.62^{(1)}$ \\
\hline 1.9 & $.57^{(4)}$ & $9.96^{(4)}$ & $6.93^{(2)}$ & $81^{(2)}$ & $9.95^{(3)}$ & $8.91^{(3)}$ & $1.31^{(1)}$ & $2.97^{(1)}$ \\
\hline 2.4 & $3.88^{(4)}$ & $16.06^{(4)}$ & $12.62^{(3)}$ & $9.96^{(3)}$ & $9.78^{(2)}$ & $7.90^{(2)}$ & $5^{5.33^{(1)}}$ & $5.94^{(1)}$ \\
\hline 2.9 & $4.44^{(4)}$ & $14.35^{(4)}$ & $13.18^{(2)}$ & $10.41^{(2)}$ & $18.34^{(3)}$ & $11.25^{(3)}$ & $4.53^{(1)}$ & $5.56^{(1)}$ \\
\hline 3.4 & $32.32^{(4)}$ & $16.89^{(4)}$ & $16.97^{(2)}$ & $12.04^{(2)}$ & $22.89^{(3)}$ & $13.02^{(3)}$ & $4.26^{(1)}$ & $5.27^{(1)}$ \\
\hline 3.9 & $31.85^{(4)}$ & $16.93^{(4)}$ & $21.97^{(2)}$ & $13.81^{(3)}$ & $22.07^{(3)}$ & $13.33^{(2)}$ & $4.58^{(1)}$ & $5.51^{(1)}$ \\
\hline 4. & $35.07^{(4)}$ & $17.85^{(4)}$ & $32.50^{(3)}$ & 16 & $14.75^{(2)}$ & $10.98^{(2)}$ & $6.92^{(1)}$ & $.97^{(1)}$ \\
\hline 4. & $25.40^{(3)}$ & 15.3 & $32.73^{(4)}$ & & $10.64^{(2)}$ & $9.34^{(2)}$ & $6.47^{(1)}$ & $6.94^{(1)}$ \\
\hline 2.4 & $11.97^{(3)}$ & $10.11^{(3)}$ & $30.07^{(4)}$ & 15. & $7.93^{(2)}$ & $7.73^{(2)}$ & $5.91^{(1)}$ & $5.86^{(1)}$ \\
\hline Ort. & $26.85^{(4)}$ & $14.44^{(4)}$ & $17.74^{(3)}$ & $11.34^{(3)}$ & $14.41^{(2)}$ & $10.13^{(2)}$ & $4.37^{(1)}$ & $5.15^{(1)}$ \\
\hline
\end{tabular}

Tablo 10'da, Durum 4 için kanal boyunca ele alınan kesitlerde elde edilen $\mathrm{OKH}$ ve $\mathrm{OMGH}$ değerlerinin ortalama değerlerine göre kanal boyunca hız alanını, DES modeli kullanılan diğer modellere kıyasla daha başarılı modellemiştir. Deneysel sonuçlar ile DES modeli kullanılarak elde edilen sayısal hız profillerinin karşılaştırılması Şekil 7'de verilmiştir. Verilen grafikler incelendiğinde, DES modeli $\mathrm{x}=60,140$ ve $190 \mathrm{~cm}$ kesitlerinde deneysel verileri tahminde çok başarılı olmuştur. Kanal girişinde $\mathrm{x}=60$ ve $140 \mathrm{~cm}$ kesitlerinde katı sınıra yakın bölgede deneysel veriden uzaklaşırken, akım derinliği boyunca bu sınırın üstünde kalan kısımda daha yakın tahminde bulunmuştur. Kanal boyunca $x=60$ ve $140 \mathrm{~cm}$ dışında kalan kesitlerde kanal tabanına yakın bölgeyi deneysel verilere yakın tahminde bulunarak bu bölgede çok başarılı olmuştur. Tablo 10 'da verilen $\mathrm{OKH}$ değeri incelendiğinde deneysel verilere en yakın tahmini $\mathrm{x}=190 \mathrm{~cm}$ kesitinde $(1.31$ $\mathrm{cm}^{2} / \mathrm{s}^{2}$ ) yaparken, en uzak tahmini de $\mathrm{x}=440 \mathrm{~cm}$ kesitinde $\left(6.92 \mathrm{~cm}^{2} / \mathrm{s}^{2}\right)$ yapmıştır.
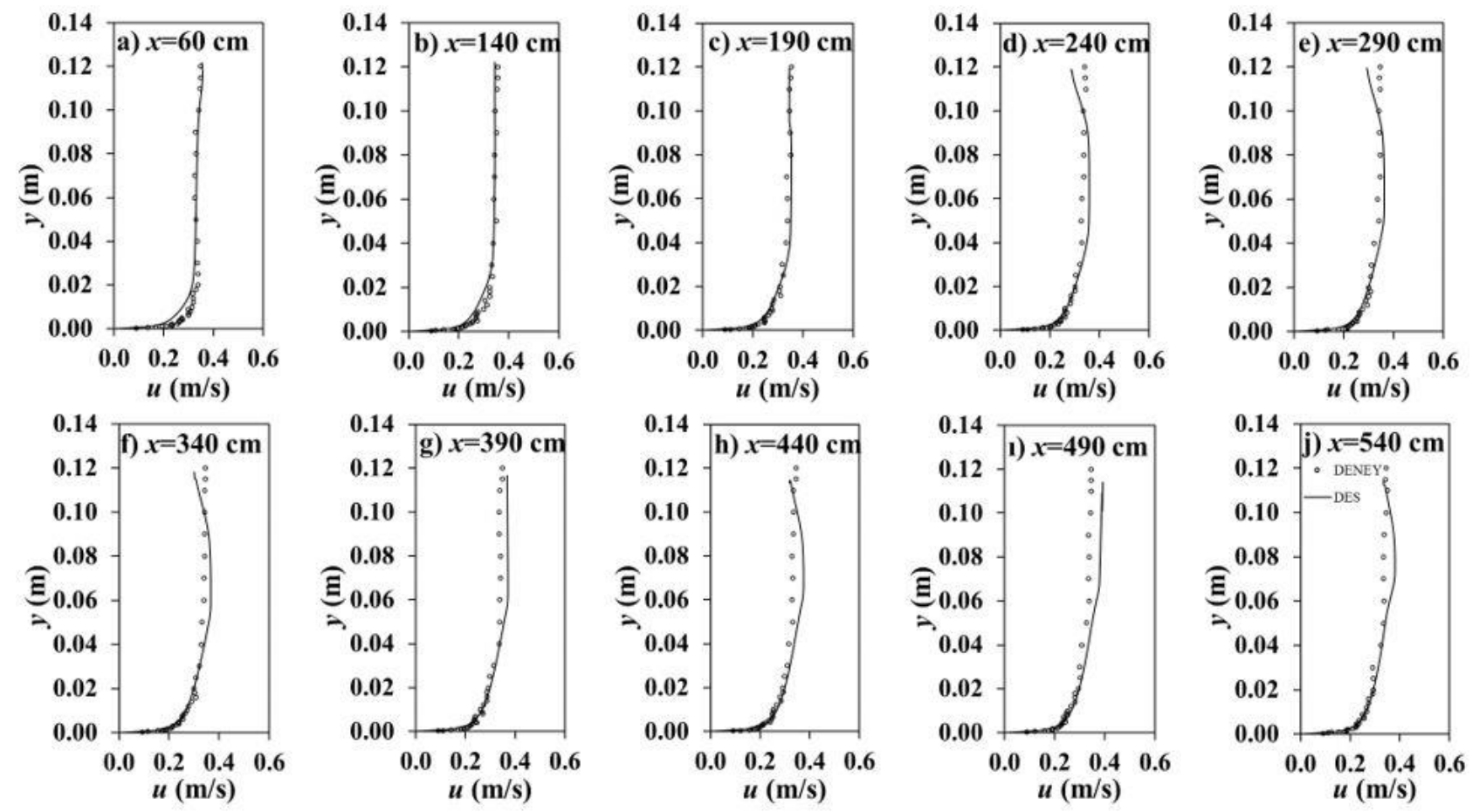

Şekil 7. Durum 4 için deneysel ve sayısal hız profilleri

Durum 5 için farklı türbülans modelleri ile elde edilen $\mathrm{OKH}$ ve $\mathrm{OMGH}$ değerleri Tablo 11'de verilmiştir. Tüm durumlar göz önünde bulundurulduğunda RNG türbülans modeli sadece
Durum 5'te başarılı olurken diğer 6 durumda deneysel verileri tahminde başarısız olmuştur. Tabloda değerler incelendiğinde, $\mathrm{x}=1.9,2.4 \mathrm{~m}$ kesitlerinde ve kanal sonlarına doğru $(\mathrm{x}=4.4,4.9$, 
$5.4 \mathrm{~m})$ toparlamış ve başarılı sonuçlar verdiği anlaşılmaktadır. Tüm kesitlerin ortalaması değerlendirildiğinde en başarılı model RNG türbülans modeli olmuş, RNG modelini SST modeli takip etmiştir. RSM ve DES model ise çok küçük fark ile de olsa RNG ve SST modellerine kıyasla başarısız olmuştur. $\mathrm{Bu}$ değerler değerlendirildiğinde, genel olarak değerlerin birbirine yakın olması ve oldukça küçük OKH ve OMGH değerlerinin elde edilmesinden kullanılan tüm türbülans modellerinin, Durum 5 için kullanıla bileceğini ifade edilebiliriz.

Tablo 11. Durum 5 için farklı türbülans modellerine göre $\mathrm{OKH}\left(\mathrm{cm}^{2} / \mathrm{s}^{2}\right)$ ve $\mathrm{OMGH}(\%)$ değerleri

\begin{tabular}{|c|c|c|c|c|c|c|c|c|}
\hline \multirow{2}{*}{$\mathbf{x}(\mathbf{m})$} & \multicolumn{2}{|c|}{ RNG } & \multicolumn{2}{|c|}{ SST } & \multicolumn{2}{|c|}{ RSM } & \multicolumn{2}{|c|}{ DES } \\
\hline & OKH & OMGH & OKH & OMGH & OKH & OMGH & ОКН & OMGH \\
\hline 0.6 & $4.44^{(3)}$ & $4.72^{(3)}$ & $4.33^{(1)}$ & $4.69^{(2)}$ & $6.70^{(4)}$ & $7.03^{(4)}$ & $4.35^{(2)}$ & $4.18^{(1)}$ \\
\hline 1.4 & $5.81^{(4)}$ & $6.78^{(4)}$ & $4.82^{(3)}$ & $5.97^{(3)}$ & $3.49^{(1)}$ & $5.13^{(1)}$ & $4.28^{(2)}$ & $5.45^{(2)}$ \\
\hline 1.9 & $2.73^{(1)}$ & $4.37^{(1)}$ & $2.81^{(2)}$ & $4.45^{(2)}$ & $4.35^{(4)}$ & $6.27^{(4)}$ & $3.43^{(3)}$ & $4.97^{(3)}$ \\
\hline 2.4 & $2.77^{(1)}$ & $4.23^{(1)}$ & $3.22^{(2)}$ & $4.79^{(2)}$ & $5.07^{(4)}$ & $6.38^{(4)}$ & $3.34^{(3)}$ & $4.99^{(3)}$ \\
\hline 2.9 & $6.24^{(2)}$ & $6.70^{(3)}$ & $6.85^{(4)}$ & $6.52^{(2)}$ & $3.04^{(1)}$ & $4.7^{(1)}$ & $6.79^{(3)}$ & $6.76^{(4)}$ \\
\hline 3.4 & $6.58^{(2)}$ & $7.38^{(4)}$ & $7.25^{(3)}$ & $7.11^{(2)}$ & $\mathbf{3 . 0 3}^{(1)}$ & $4.7^{(1)}$ & $7.42^{(4)}$ & $7.20^{(3)}$ \\
\hline 3.9 & $5.03^{(2)}$ & $6.69^{(2)}$ & $6.01^{(3)}$ & $6.79^{(3)}$ & $3.72^{(1)}$ & $5.47^{(1)}$ & $7.11^{(4)}$ & $7.71^{(4)}$ \\
\hline 4.4 & $3.22^{(1)}$ & $5.31^{(1)}$ & $4.09^{(2)}$ & $5.78^{(2)}$ & $6.49^{(4)}$ & $7.37^{(4)}$ & $6.12^{(3)}$ & $7.24^{(3)}$ \\
\hline 4.9 & $3.63^{(1)}$ & $5.47^{(1)}$ & $4.72^{(2)}$ & $6.21^{(2)}$ & $7.44^{(3)}$ & $7.62^{(3)}$ & $8.67^{(4)}$ & $8.56^{(4)}$ \\
\hline 5.4 & $2.00^{(1)}$ & $3.20^{(1)}$ & $2.80^{(2)}$ & $4.17^{(2)}$ & $9.31^{(4)}$ & $8.84^{(3)}$ & $9.15^{(3)}$ & $9.19^{(4)}$ \\
\hline Ort. & $4.25^{(1)}$ & $5.48^{(1)}$ & $4.69^{(2)}$ & $5.65^{(2)}$ & $5.26^{(3)}$ & $6.35^{(3)}$ & $6.06^{(4)}$ & $6.62^{(4)}$ \\
\hline
\end{tabular}

Şekil 8'de, Durum 5 için kanal boyunca ele alınan kesitlerde elde edilen $\mathrm{OKH}$ ve OMGH değerinin ortalamasina göre deneysel hiz profillerine en yakın tahminde bulunan RNG modeli ile elde edilen sayısal hız profillerinin deneysel sonuçlar ile grafiksel karşılaştırılması verilmiştir. Tüm diğer durumlar incelendiğinde, RNG modeli sadece Durum 5'te başarılı olmuştur. Şekil 8 incelendiğinde, RNG modeli, kanal giriş bölgesinde $\mathrm{x}=60,140$ ve $190 \mathrm{~cm}$ kesitlerinde kat1 sınıra ve su yüzüne yakın bölgenin dişında (akım derinliğinin orta kısmında) deneysel veriye yakın tahminde bulunmuştur. Bu kesitlerden sonra RNG modelinin, serbest su yüzüne doğru deneysel verilere yakın tahminde bulunduğu görülmektedir.
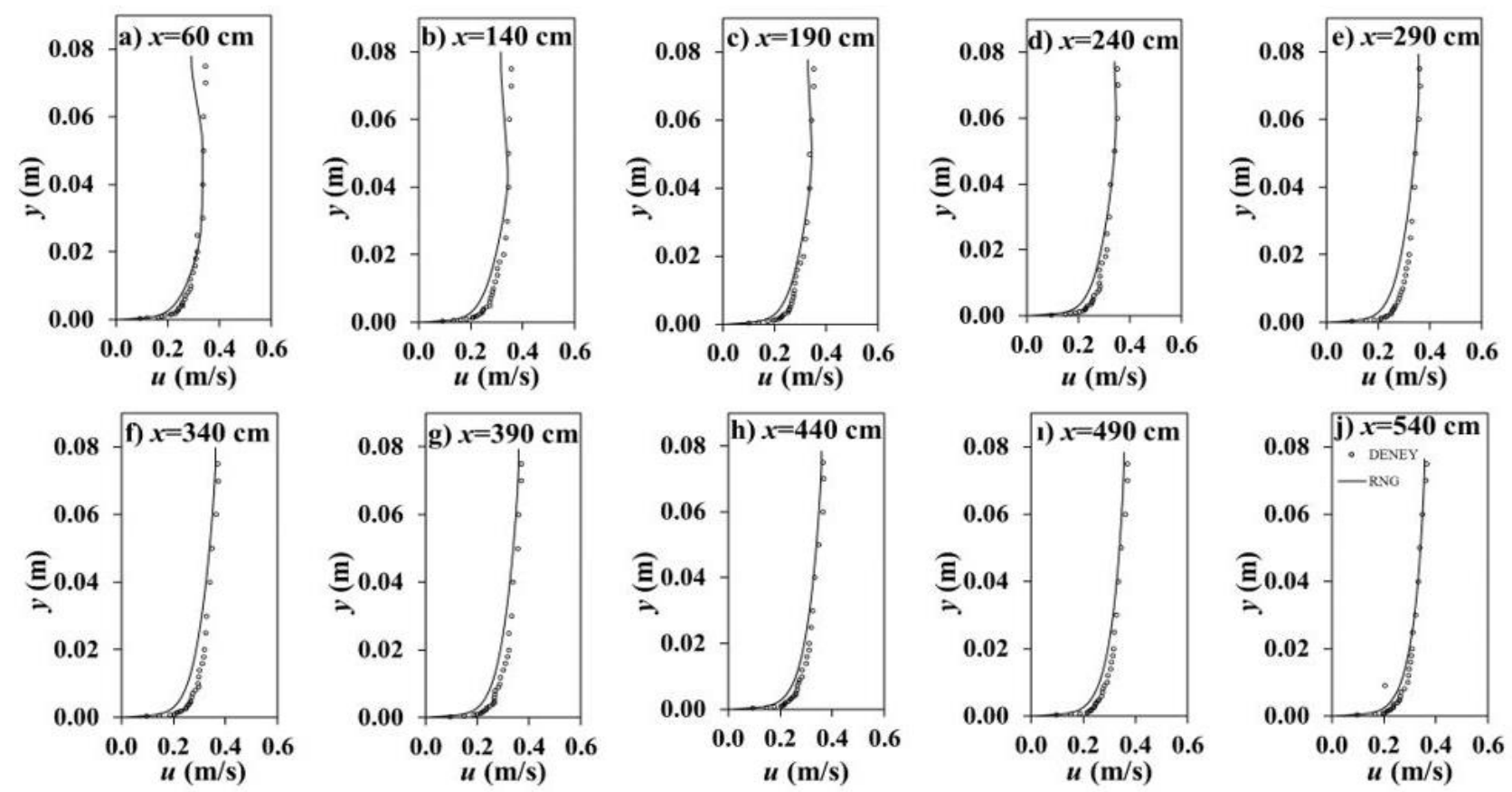

Şekil 8. Durum 5 için deneysel ve sayısal hız profilleri 
Durum 6 için farklı türbülans modelleri ile elde edilen $\mathrm{OKH}$ ve $\mathrm{OMGH}$ değerleri Tablo 12 'de verilmiştir. SST türbülans modeli kanal girişinde en başarılı model olurken, $\mathrm{x}=4.9$ ve $5.4 \mathrm{~m}$ kesitlerinde DES en başarılı model olmuştur. SST türbülans modelinin $\mathrm{OKH}$ değerleri kanal girişinde ( $\mathrm{x}=0,6 \mathrm{~m}$ kesitinde) 1.27 iken, kanal sonlanına doğru başarılı olduğu kesitlerde giderek bu değer küçülmüş yani deneysel değerleri tahmin başarısı artmıştır. $\mathrm{x}=4.9$ ve $5.4 \mathrm{~m}$ kesitlerinde değerler artmış, dolayısıyla tahminde başarılı olmamıştır. SST modeli 10 kesitin sekizinde başarılı olurken iki kesitte başarısız olmuştur. Son satırda verilen, ele alınan tüm kesitlerde elde edilen $\mathrm{OKH}$ ve OMGH değerlerinin ortalamasına bakıldığında SST modeli en başarılı model olmuştur. Tüm kesitlerin ortalamalarında deneysel verileri tahminde başarı sıralaması SST, DES, RNG ve RSM şeklinde olmuştur.

Tablo 12. Durum 6 için farklı türbülans modellerine göre $\mathrm{OKH}\left(\mathrm{cm}^{2} / \mathrm{s}^{2}\right)$ ve OMGH $(\%)$ değerleri

\begin{tabular}{|c|c|c|c|c|c|c|c|c|}
\hline \multirow{2}{*}{$\mathbf{x}(\mathbf{m})$} & \multicolumn{2}{|c|}{ RNG } & \multicolumn{2}{c|}{ SST } & \multicolumn{2}{c|}{ RSM } & \multicolumn{2}{c|}{ DES } \\
\cline { 2 - 8 } & OKH & OMGH & OKH & OMGH & OKH & OMGH & OKH & OMGH \\
\hline $\mathbf{0 . 6}$ & $1.72^{(3)}$ & $6.76^{(3)}$ & $\mathbf{1 . 2 7}^{(\mathbf{1})}$ & $\mathbf{6 . 2 6}^{(\mathbf{1})}$ & $1.81^{(4)}$ & $7.09^{(4)}$ & $1.31^{(2)}$ & $6.44^{(2)}$ \\
\hline $\mathbf{1 . 4}$ & $1.59^{(3)}$ & $6.04^{(3)}$ & $\mathbf{0 . 9 0}^{(\mathbf{1})}$ & $\mathbf{4 . 3 4}^{(\mathbf{1})}$ & $1.79^{(4)}$ & $6.19^{(4)}$ & $1.18^{(2)}$ & $5.08^{(2)}$ \\
\hline $\mathbf{1 . 9}$ & $1.28^{(3)}$ & $5.64^{(3)}$ & $\mathbf{0 . 6 3}^{(\mathbf{1})}$ & $\mathbf{3 . 8 7}^{(\mathbf{1})}$ & $1.55^{(4)}$ & $6.15^{(4)}$ & $0.96^{(2)}$ & $4.98^{(2)}$ \\
\hline $\mathbf{2 . 4}$ & $1.01^{(3)}$ & $5.28^{(3)}$ & $\mathbf{0 . 6 1}^{(\mathbf{1})}$ & $\mathbf{4 . 2 0}^{(\mathbf{1})}$ & $1.33^{(4)}$ & $6.07^{(4)}$ & $0.79^{(2)}$ & $4.80^{(2)}$ \\
\hline $\mathbf{2 . 9}$ & $1.72^{(3)}$ & $7.14^{(4)}$ & $\mathbf{0 . 7 0}^{(\mathbf{1})}$ & $\mathbf{4 . 4 3}^{(\mathbf{1})}$ & $1.77^{(4)}$ & $6.95^{(3)}$ & $1.41^{(2)}$ & $6.54^{(2)}$ \\
\hline $\mathbf{3 . 4}$ & $1.63^{(3)}$ & $6.91^{(4)}$ & $\mathbf{0 . 5 4}^{(\mathbf{1})}$ & $\mathbf{3 . 8 5}^{(\mathbf{1})}$ & $1.65^{(4)}$ & $6.73^{(3)}$ & $1.32^{(2)}$ & $6.38^{(2)}$ \\
\hline $\mathbf{3 . 9}$ & $1.35^{(3)}$ & $6.16^{(4)}$ & $\mathbf{0 . 4 0}^{(\mathbf{1})}$ & $\mathbf{2 . 9 1}^{(\mathbf{1})}$ & $1.39^{(4)}$ & $6.01^{(3)}$ & $1.08^{(2)}$ & $5.79^{(2)}$ \\
\hline $\mathbf{4 . 4}$ & $0.91^{(3)}$ & $4.96^{(4)}$ & $\mathbf{0 . 3 6}^{(\mathbf{1})}$ & $\mathbf{3 . 1 5}^{(\mathbf{1})}$ & $0.97^{(4)}$ & $4.82^{(3)}$ & $0.75^{(2)}$ & $4.74^{(2)}$ \\
\hline $\mathbf{4 . 9}$ & $0.80^{(2)}$ & $4.47^{(2)}$ & $0.81^{(3)}$ & $5.07^{(4)}$ & $0.96^{(4)}$ & $4.73^{(3)}$ & $\mathbf{0 . 5 3}^{(\mathbf{1})}$ & $\mathbf{3 . 3 6}^{(\mathbf{1})}$ \\
\hline $\mathbf{5 . 4}$ & $0.63^{(2)}$ & $3.84^{(2)}$ & $0.75^{(3)}$ & $5.00^{(4)}$ & $0.79^{(4)}$ & $3.90^{(3)}$ & $\mathbf{0 . 5 1}^{(\mathbf{1})}$ & $\mathbf{3 . 7 0}^{(\mathbf{1})}$ \\
\hline $\mathbf{O r t .}$ & $1.26^{(3)}$ & $5.72^{(3)}$ & $\mathbf{0 . 7 0}^{(\mathbf{1})}$ & $\mathbf{4 . 3 1}^{(\mathbf{1})}$ & $1.40^{(4)}$ & $5.86^{(4)}$ & $0.98^{(2)}$ & $5.18^{(2)}$ \\
\hline
\end{tabular}

Tablo 12'de Durum 6 için son satırda verilen OKH ve OMGH ortalama değerlerine göre kanal boyunca hız alanını, DES modeli diğer modellere kıyasla daha başarılı modellemiştir. Deneysel sonuçlar ile DES modeli kullanılarak elde edilen sayısal hız profillerinin karşılaştırılması Şekil 9'da verilmiştir. Verilen grafikler incelendiğinde, kanal tabanına yakın bölgede deneysel verilerle uyum azken, kanal tabanından uzaklaştıkça akım derinliğinin artmasıyla hız profilleri arasındaki uyum çok iyi olmuştur. Durum 6 için tüm kesitler kıyaslandığında en iyi uyum $\mathrm{x}=440 \mathrm{~cm}$ kesitinde olmuş ve tüm akım derinliği boyunca uyum çok iyi olmuştur.
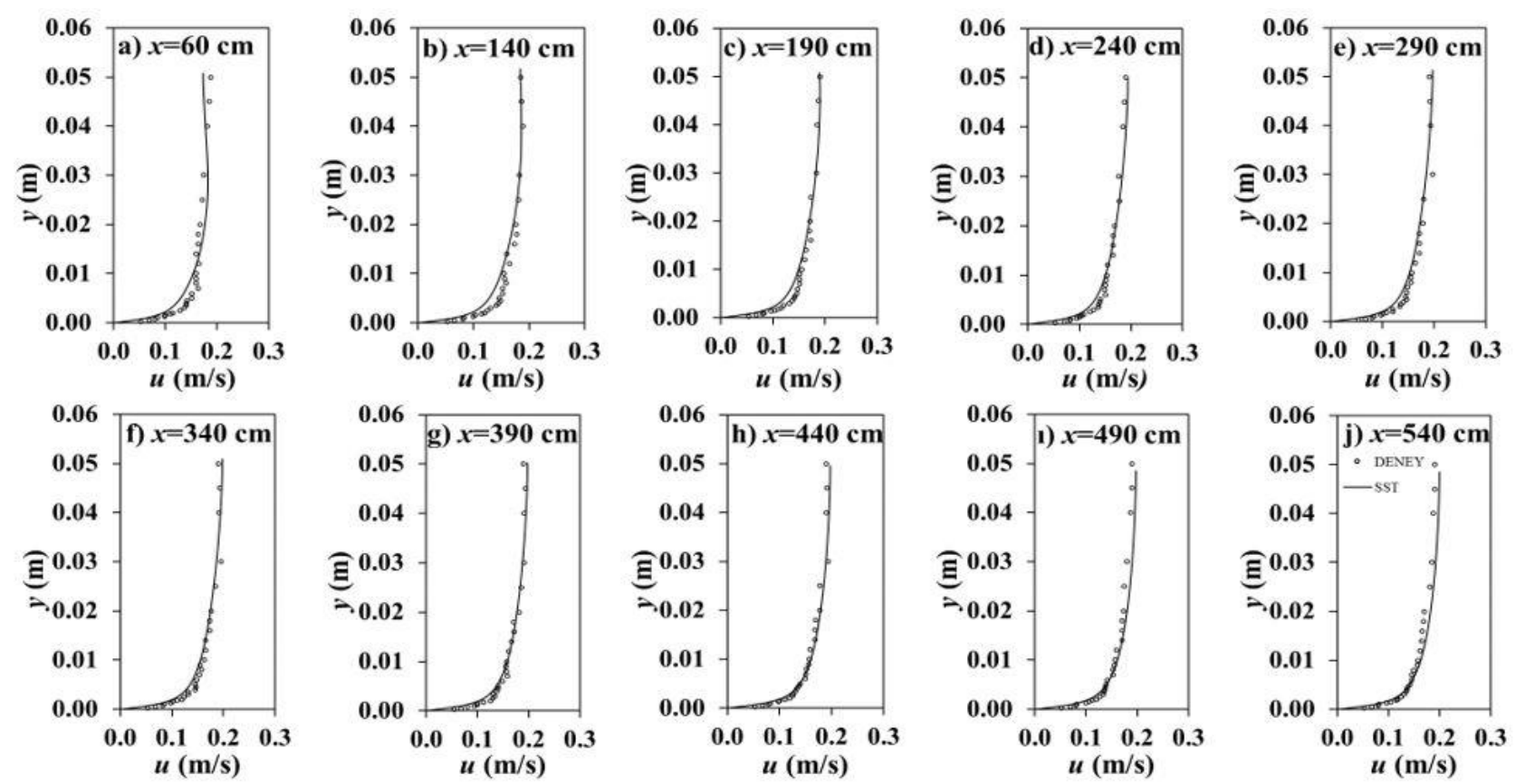

Şekil 9. Durum 6 için deneysel ve sayısal hız profilleri 
Tablo 13'te, Durum 7 için farklı türbülans modelleri ile elde edilen $\mathrm{OKH}$ ve $\mathrm{OMGH}$ değerleri verilmiştir. Tablo 13'te verilen $\mathrm{OKH}$ değerleri incelendiğinde, deneysel verilere en yakın tahmini $\mathrm{x}=190 \mathrm{~cm}$ kesitinde $\left(0.62 \mathrm{~cm}^{2} / \mathrm{s}^{2}\right)$ yaparken en uzak tahmini de $\mathrm{x}=340 \mathrm{~cm}$ kesitinde $\left(6.34 \mathrm{~cm}^{2} / \mathrm{s}^{2}\right)$ yapmıştır. Bu sonuç, grafiksel karşılaştırmadan da görülmektedir. RNG türbülans modeli hiçbir kesitte başarılı olmazken, RSM türbülans modeli $\mathrm{x}=3.4$ m'de, DES türbülans modeli $\mathrm{x}=1.9,2.4,3.9$ ve 4.4 m'de ve SST türbülans modeli $\mathrm{x}=0.6,1.4$, $2.9,4.9$ ve 5.4 m'de en başarılı olmuştur. Kullanılan modellerin başarı sıralaması SST, DES, RSM ve RNG şeklinde olmuştur.

Tablo 13. Durum 7 için farklı türbülans modellerine göre $\mathrm{OKH}\left(\mathrm{cm}^{2} / \mathrm{s}^{2}\right)$ ve $\mathrm{OMGH}(\%)$ değerleri

\begin{tabular}{|c|c|c|c|c|c|c|c|c|}
\hline \multirow{2}{*}{$\mathbf{x}(\mathbf{m})$} & \multicolumn{2}{|c|}{ RNG } & \multicolumn{2}{c|}{ SST } & \multicolumn{2}{c|}{ RSM } & \multicolumn{2}{c|}{ DES } \\
\cline { 2 - 8 } & $\mathbf{O K H}$ & $\mathbf{O M G H}$ & $\mathbf{O K H}$ & $\mathbf{O M G H}$ & $\mathbf{O K H}$ & $\mathbf{O M G H}$ & $\mathbf{O K H}$ & OMGH \\
\hline $\mathbf{0 . 6}$ & $3.29^{(4)}$ & $7.74^{(4)}$ & $\mathbf{1 . 7 3}^{(\mathbf{1})}$ & $\mathbf{5 . 5 5}^{(\mathbf{1})}$ & $2.00^{(3)}$ & $5.94^{(3)}$ & $1.76^{(2)}$ & $5.58^{(2)}$ \\
\hline $\mathbf{1 . 4}$ & $4.07^{(4)}$ & $9.27^{(4)}$ & $\mathbf{1 . 0 5}^{(\mathbf{1})}$ & $3.67^{(2)}$ & $1.48^{(3)}$ & $4.40^{(3)}$ & $1.06^{(2)}$ & $\mathbf{3 . 5 5}^{(\mathbf{1})}$ \\
\hline $\mathbf{1 . 9}$ & $3.28^{(4)}$ & $8.35^{(4)}$ & $0.62^{(2)}$ & $2.91^{(2)}$ & $1.20^{(3)}$ & $4.42^{(3)}$ & $\mathbf{0 . 6 0}^{(\mathbf{1})}$ & $\mathbf{2 . 7 0}^{(\mathbf{1})}$ \\
\hline $\mathbf{2 . 4}$ & $1.97^{(4)}$ & $6.08^{(4)}$ & $0.71^{(2)}$ & $3.40^{(2)}$ & $1.69^{(3)}$ & $5.62^{(3)}$ & $\mathbf{0 . 7 1}^{(\mathbf{1})}$ & $\mathbf{3 . 3 6}^{(\mathbf{1})}$ \\
\hline $\mathbf{2 . 9}$ & $3.59^{(4)}$ & $8.58^{(4)}$ & $\mathbf{1 . 1 1}^{(\mathbf{1})}$ & $\mathbf{4 . 1 5}^{(\mathbf{1})}$ & $1.47^{(3)}$ & $4.72^{(3)}$ & $1.19^{(2)}$ & $4.24^{(2)}$ \\
\hline $\mathbf{3 . 4}$ & $7.34^{(4)}$ & $13.19^{(4)}$ & $6.34^{(2)}$ & $10.68^{(2)}$ & $\mathbf{6 . 3 4}^{(\mathbf{1})}$ & $\mathbf{1 0 . 3 3}^{(\mathbf{1})}$ & $6.36^{(3)}$ & $10.78^{(3)}$ \\
\hline $\mathbf{3 . 9}$ & $2.08^{(4)}$ & $6.16^{(4)}$ & $1.03^{(2)}$ & $3.94^{(2)}$ & $1.32^{(3)}$ & $4.64^{(3)}$ & $\mathbf{0 . 9 8}^{(\mathbf{1})}$ & $\mathbf{3 . 5 5}^{(\mathbf{1})}$ \\
\hline $\mathbf{4 . 4}$ & $1.34^{(3)}$ & $4.25^{(3)}$ & $0.69^{(2)}$ & $\mathbf{2 . 5 1}^{(\mathbf{1})}$ & $1.58^{(4)}$ & $5.10^{(4)}$ & $\mathbf{0 . 6 7}^{(\mathbf{1})}$ & $2.56^{(2)}$ \\
\hline $\mathbf{4 . 9}$ & $1.11^{(3)}$ & $3.77^{(3)}$ & $\mathbf{0 . 7 0}^{(\mathbf{1})}$ & $\mathbf{2 . 5 7}^{(\mathbf{1})}$ & $1.88^{(4)}$ & $5.66^{(4)}$ & $0.76^{(2)}$ & $2.96^{(2)}$ \\
\hline $\mathbf{5 . 4}$ & $1.01^{(3)}$ & $3.73^{(2)}$ & $\mathbf{0 . 8 6}^{(\mathbf{1})}$ & $\mathbf{3 . 6 5}^{(\mathbf{1})}$ & $3.02^{(4)}$ & $7.57^{(4)}$ & $0.95^{(2)}$ & $4.01^{(3)}$ \\
\hline Ort. & $2.91^{(4)}$ & $7.11^{(4)}$ & $\mathbf{1 . 4 9}^{(\mathbf{1})}$ & $\mathbf{4 . 3 0}^{(\mathbf{1})}$ & $2.20^{(3)}$ & $5.84^{(3)}$ & $1.51^{(2)}$ & $4.33^{(2)}$ \\
\hline
\end{tabular}

Durum 7 için deneysel sonuçlar ile SST modelinden elde edilen hiz profillerinin karşılaştırılması Şekil 10'da verilmiştir. Şekiller incelendiğinde, SST modelinin kanal boyunca ele alınan kesitlerde deneysel verilere yakın sonuçlar verdiği, ancak katı sinıra yakın olan bölgede deneysel verilerden uzaklaştı̆̆ görülmüştür. Ayrica, sayısal ve deneysel sinır tabakası kalınlıklarının birbirinden farklılık gösterdiği ifade edilebilir. Katı sınıra yakın bölgede sayısal hız değerlerinin deneysel hız verilerinden küçük olduğu görülmektedir. Kanal girişinde $\mathrm{x}=60 \mathrm{~cm}$ kesitinde sınır tabakasının üst tarafını deneysel hız verilerinden büyük tahmin ederken diğer kesitlerde nispeten küçük tahminde bulunmuştur.
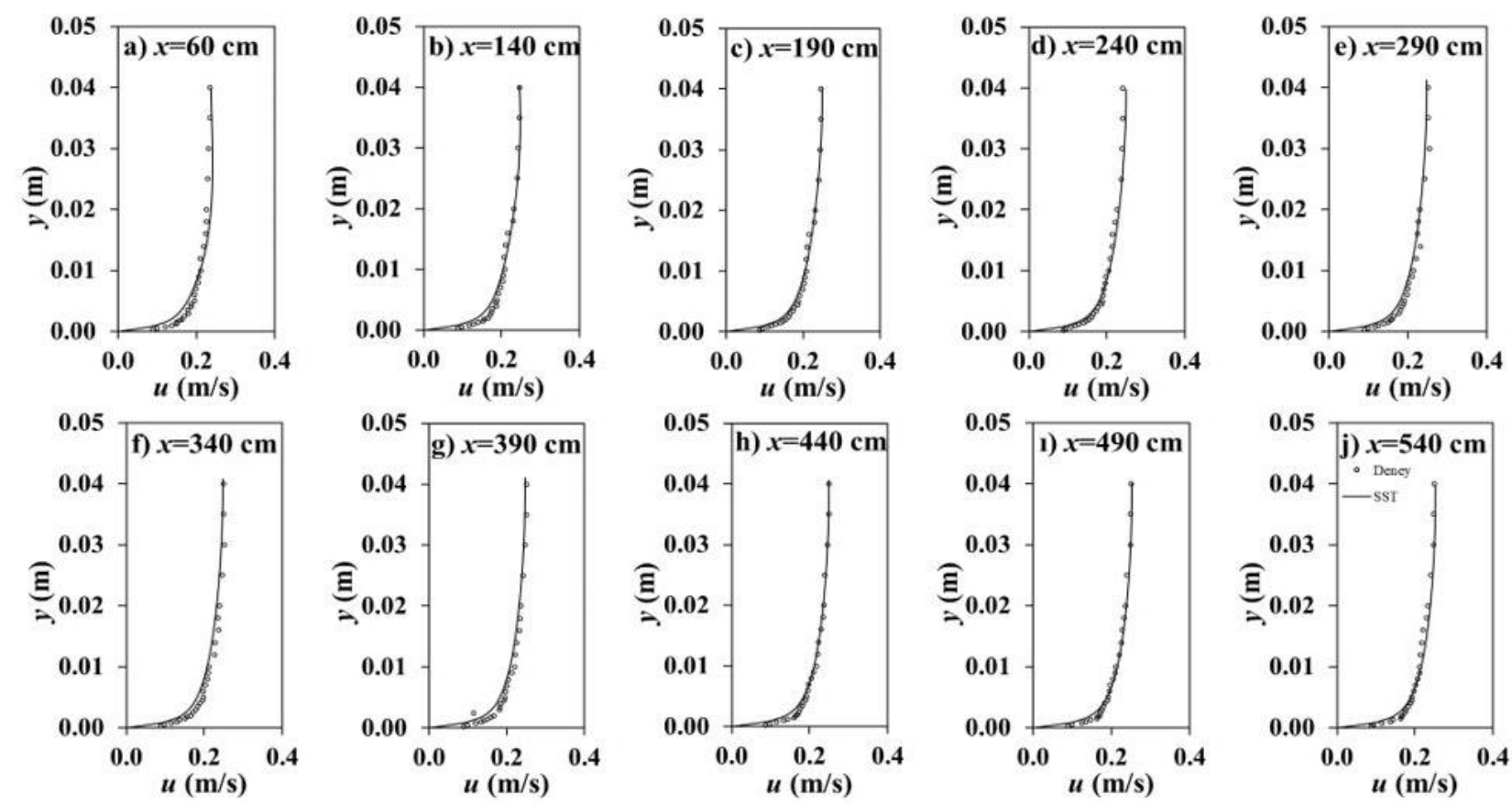

Şekil 10. Durum 7 için deneysel ve sayısal hız profilleri 


\subsection{Sayısal hız kontörleri}

Deneysel ve farklı türbülans modelleri kullanılarak elde edilen sayısal hız profillerinin karşılaştırılması sonucunda en küçük OKH ve OMGH değerlerinin elde edildiği türbülans modelinde elde edilen yatay hız bileşeninin kanal boyunca dağılımı Şekil 11'de verilmiştir. Farklı akım koşullarında elde edilen hız kontörlerinin karşılaştırılması için değişim aralığı aynı değerlendirilmiştir.
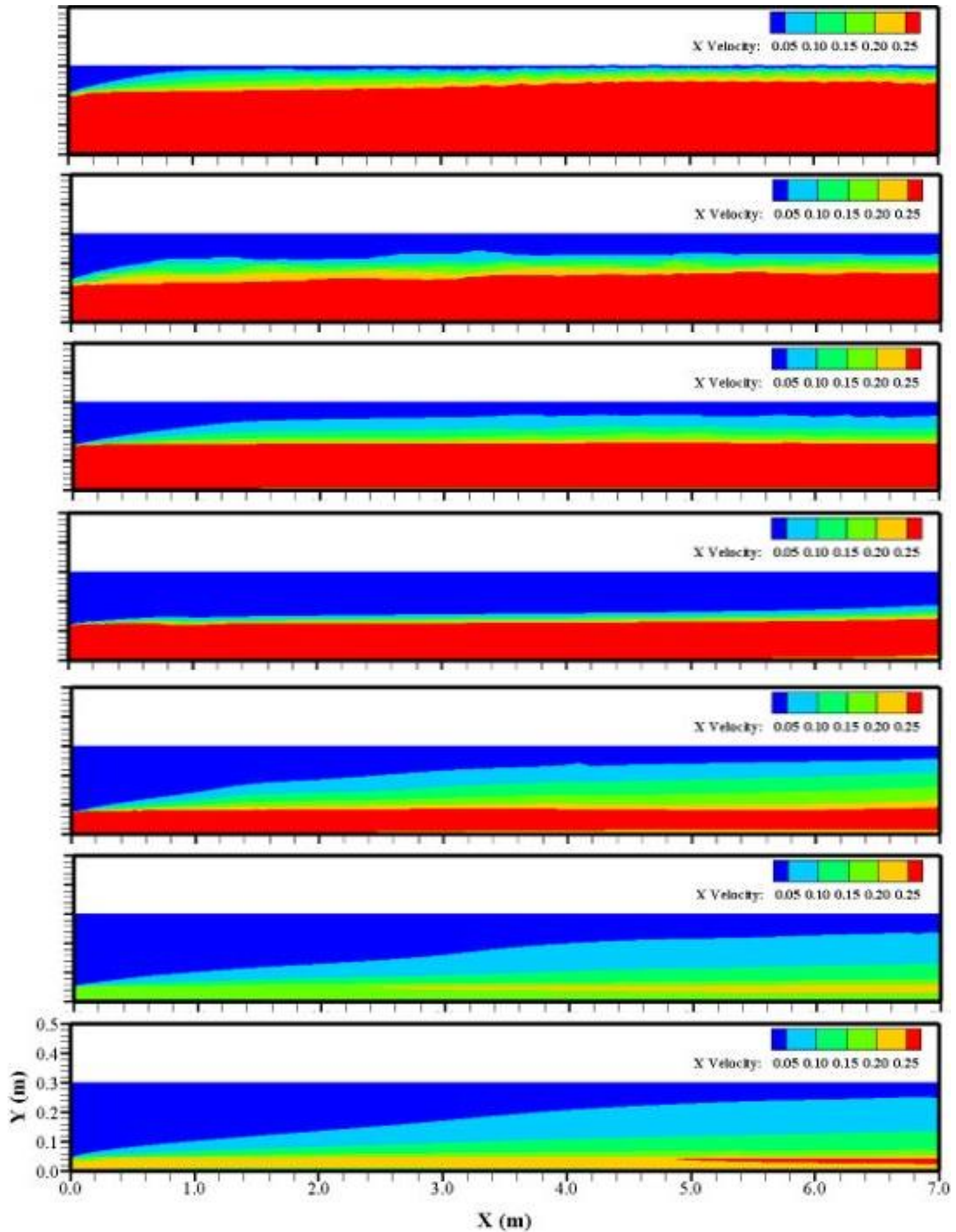

Şekil 11. Farklı akım durumları için sayısal hız kontörleri 
Şekil 11'de verilen grafikler incelendiğinde beklenildiği gibi maksimum akım hızlarının kanal tabanına yakın bölgede oluştuğu, akım debisinin ve akım derinliğinin azalmasıyla maksimum hızın oluştuğu bölgenin azaldığ 1 görülmektedir. Durum 1 'de elde edilen hız kontörlerinin incelendiğinde, $0.1 \mathrm{~m} / \mathrm{s}$ hızın oluştuğu bölgenin hemen hemen su yüzüne ulaştığı söylenebilir. Kanal tabanının eğimli olduğu durumda elde edilen hız kontörlerinde, kanal eğiminin hız alanı üzerinde etkisinin bulunduğu görülmektedir.

\section{Sonuçlar}

Bu çalışmada, eğimli kritik altı açık kanal akımının farklı türbülans modelleri kullanılarak sayısal modellemesi yapılmıştır. Akımın hareketini kontrol eden süreklilik ve momentum denklemleri sonlu hacimler yöntemine dayalı çözüm yapan ANSYS Fluent paket programı yardımıyla çözülmüş ve akım profilinin belirlenmesinde ise Akışkan Hacimleri Yöntemi kullanılmıştır. Sayısal modellemede, türbülansın çözümünde ReNormalization Group (RNG), Shear Stress Transport (SST), Reynolds Stress Model (RSM) ve Detehade Eddy Simülasyon (DES) modelleri kullanılmıştır. Ağ yapısının sayısal sonuçlar üzerindeki etkisinin olup olmadığının belirlenmesi için Ağ Yakınsama İndeksi yöntemi kullanılmış ve elde edilen sonuçlardan sayısal model sonuçlarının ağ yapısından bağımsızlaştığı belirlenmiştir. Farklı akım şartlarında, farklı türbülans kapatma modelleri kullanılarak sayısal olarak elde edilen sayısal hiz profilleri deneysel sonuçlarla karşılaştırılmıştır. Karşılaştırmalarda, niceliksel kriter olarak Ortalama Karesel Hata ve Ortalama Mutlak Göreceli Hata değerleri kullanılmıştır. Durum 1'de en başarılı model olan SST için OKH ve OMGH değerleri sirasiyla 5.09 ve 5.25, Durum 2'de en başarılı model olan DES için OKH ve OMGH değerleri sirasiyla 42.04 ve 5.09, Durum 3 'te $\mathrm{OKH}$ kriterine göre en başarılı model olan $\mathrm{RSM}$ için $\mathrm{OKH}$ değeri 4.10 ve OMGH kriterine göre en başarılı model olan DES için OMGH değeri 4.85, Durum 4'te en başarılı model olan DES için OKH ve OMGH değerleri sırasıyla 4.37 ve 5.15, Durum 5'te en başarılı model olan RNG için $\mathrm{OKH}$ ve $\mathrm{OMGH}$ değerleri sirasıyla 4.25 ve 5.48, Durum 6'da en başar1lı model olan SST için $\mathrm{OKH}$ ve OMGH değerleri sirasıyla 0.70 ve 4.31 ve Durum 7'de en başarılı model olan SST için OKH ve OMGH değerleri sirasıyla 1.49 ve 4.30 olarak elde edilmiştir. Çalışma sonucunda, RNG ve RSM modelleri sadece bir akım durumunda, SST modeli üç farklı akım durumunda ve DES modeli ise iki farklı akım durumunda, kullanılan diğer modellere kıyasla daha başarılı olmuştur. Elde edilen sonuçlardan, $\mathrm{OKH}$ ve $\mathrm{OMGH}$ değerlerinin çok küçük farklılıklar göstermesinden dolayı hafif eğimli kritik altı açık kanal akımının sayısal çözümünde SST modelinin başarılı bir şekilde kullanılabileceği belirlenmiştir.

\section{Teșekkür}

$\mathrm{Bu}$ çalışma, Harran Üniversitesi, Bilimsel Araştırma Projeleri birimi (HÜBAP) tarafindan 18197 numaralı proje ile maddi olarak desteklenmiştir.

\section{Kaynaklar}

Akoz, M. S., Şimşek, O. and Soydan, N. G. (2019). Numerical modeling of interaction of turbulent flow with a buried circular cylinder on a plane surface. Teknik Dergi, 30(6), 9621-9645.

Ayhan, İ, Şimşek, O., Gümüş, V. and Avşaroğlu, Y. (2020). H2 su yüzü profiline sahip açık kanal akımının sayısal modellemesi. Euroasia Journal of Mathematics-Engineering Natural \& Medical Sciences, 8(1), 33-42.

Bal, Ş. (2019). Değişken Enkesitli Açık Kanal Akımının Deneysel ve Sayısal Modellemesi. Yüksek Lisans Tezi, Harran Üniversitesi Fen Bilimleri Enstitüsü. Şanlıurfa.

Gumus, V., Simsek, O., Soydan, N. G., Akoz, M. S. and Kırkgoz, M. S. (2016). Numerical modeling of submerged hydraulic jump from a sluice gate. Journal of Irrigation and Drainage Engineering, 142(1), 04015037.

Gümüş, V. (2014). Dolusavak Akımının Saylsal Modellemesi. Doktora Tezi, Çukurova Üniversitesi Fen Bilimleri Enstitüsü. Adana.

Hirt, C. W. and Nichols, B. D. (1981). Volume of fluid (vof) method for the dynamics of free boundaries. Journal of Computational Physics, 39(1), 201-225.

Kırkgöz, M. S. (2018). Çözülmüş problemlerle akışkanlar mekaniği. İstanbul: Birsen Kitabevi.

Launder, B. E., Reece, G. J. and Rodi, W. (1975). Progress in the development of a reynolds-stress turbulence closure. Journal of Fluid Mechanics, 68(3), 537-566.

Menter, F. R. (1994). 2-equation eddy-viscosity turbulence models for engineering applications. AIAA Journal, 32(8), 1598-1605.

Roache, P. J. (1994). Perspective-a method for uniform reporting of grid refinement studies. Journal of Fluids Engineering-Transactions of the ASME, 116(3), 405-413. 
Roache, P. J. (1998). Verification of codes and calculations. AIAA Journal, 36(5), 696-702.

Simsek, O., Akoz, M. S. and Soydan, N. G. (2016). Numerical validation of open channel flow over a curvilinear broad-crested weir. Progress in Computational Fluid Dynamics An International Journal, 16(6), 364-378.

Soydan Oksal, N. G., Akoz, M. S. and Simsek, O. (2020). Numerical modelling of trapezoidal weir flow with rans, les and des models. Sadhana, 45(91), 1-18.
Soydan, N. G., Şimşek, O. and Aköz, M. S. (2017). Prediction and validation of turbulent flow around a cylindrical weir. European water, 57, 85-92.

Yakhot, V. and Orszag, S. A. (1986). Renormalization group analysis of turbulence I. Basic theory. Journal of Scientific Computing, 1(1), 3-51.

Yakhot, V., Orszag, S. A., Thangam, S., Gatski, T. B. and Speziale, C. G. (1992). Development of turbulence models for shear flows by a double expansion technique. Physics of Fluids a-Fluid Dynamics, 4(7), 1510-1520. 